\title{
LOS OFICIOS RELACIONADOS CON LA MEDICINA DURANTE LA BAJA EDAD MEDIA EN LA CORONA DE ARAGÓN Y SU PROYECCIÓN SOCIAL ${ }^{1}$
}

\author{
THE OCCUPATIONS RELATED TO MEDICINE \\ DURING THE LATER MIDDLE AGES IN \\ THE CROWN OF ARAGON AND THEIR SOCIAL PROJECTION
}

\author{
CARMEL FERRAGUd DOMINGO \\ C.C. Maria Auxiliadora (Algemesí, València)
}

Resumen: En el presente artículo se intenta caracterizar el grupo de individuos que hicieron de la medicina la ocupación más importante de sus vidas y de la cual vivían, desde los más famosos y acaudalados físicos que trabajaban en la ciudad, hasta los humildes barberos rurales, pasando por las mujeres y los curanderos, también desde la práctica de los miembros de las tres grandes religiones que se cruzaron en la Corona de Aragón: cristianos, judíos y musulmanes. Se analiza en qué consistía su actividad médica y dónde y cómo se desarrollaba. En segundo lugar, se da un paso más allá de la medicina para tratar un aspecto que los historiadores de la medicina no suelen plantearse respecto a los sanadores excepto en ocasiones puntuales: su actividad económica, política y social.

Palabras clave: Promoción social; Prestigio; Religiosidad; Cultura médica; Profesionalización; Minorías religiosas; Salario; Práctica médica.

\begin{abstract}
In this article we try to characterize the group of people who made of medicine the most important occupation of their lives and their way of living, from the richest and the most affluent physics who worked in the city, to the rural barbers, going by women and quacks and also from the practice of the members of the three great religions that crossed the Crown of Aragon: Christians, Jewish and Muslims. It is analysed the medical activity, what it consists of, where and how it was developed. Second, we try to go beyond medicine to deal with an aspect that medicine historians (chroniclers) are not used to raise, except in particular situations, related with healers: their economical, political and social activity.
\end{abstract}

Keywords: Social promotion; Prestige; Religiousness; Medical culture; Professionalization; Religious minorities; Wages; Medical practice.

${ }^{1}$ El presente artículo es una versión de la conferencia presentada bajo el título "Los oficios relacionados con la medicina en la Edad Media y el Renacimiento" en el curso La asistencia sanitaria en la Edad Media y el Renacimiento, dirigido por el Dr. Angel Luis Molina y la Dra Mar, de la Universidad de Murcia [San Pedro del Pinatar; del 19 al 23 de septiembre de 2005]. Quisiera agradecer al Dr. Jon Arrizabalaga sus comentarios.

Las siglas utilizadas han sido las siguientes: $A C A=$ Arxiu de la Corona d'Aragó; $C=$ Cancelleria; $\mathrm{MR}=\mathrm{Mestre}$ Racional; $\mathrm{ACP}=$ Arxiu Comarcal de Puigcerdà; AHPM $=$ A Arxiu Cancelleria; $M R=$ Mestre Racional; $A C P=$ Arxiu Comarcal de Puigcerdà; AHPM $=$ Arxiu
Historic de Protocols de Manresa; AHG $=$ Arxiu Historic de Girona; AMS = Arxiu Municipal Historic de Protocols de Manresa; AHG = Arxiu Historic de Girona; AMS = Arxiu Municipal
de Sueca; JHM= Journal of the history of medicine; BSCC = Boletín de la Sociedad Castellonense de Sueca; JHM = Journal of the history of medicine; $\mathrm{BSCC}=$ Boletín de la Sociedad Castellonense
de Cultura; ATCA $=$ Arxiu de Textos Catalans Antics; BAH = Boletín de la Academia de la Historia; BRABL = Boletín de la Real Academia de Buenas Letras de Barcelona. 


\section{SUMARIO}

Introducción.- I. Las ocupaciones relacionadas con la salud.- II. El triunfo del galenismo y sus practicantes.- III. Desniveles de riqueza y promoción social.- IV Los sanadores dentro del poder político.- V. Las inversiones económicas y la ostentación de la riqueza.- Apéndices.

\section{INTRODUCCIÓN}

Durante la Baja Edad Media, la Corona de Aragón se había convertido en un estado con una gran pujanza comercial e industrial, con un extraordinario desarrollo del mercado, gracias sobretodo a una dinámica clase burguesa. Era un estado con clara vocación marinera de apertura al Mediterráneo, en expansión. Aunque no se puede olvidar que todo esto se dio en el marco de una sociedad feudal y con unas relaciones peculiares que la caracterizaron, el rígido sistema de los tres órdenes se estaba resquebrajando, y continuaba una dependencia estructural sobre el medio ambiente. Debemos recordar que aquellos fueron tiempos donde se experimentaron numerosas crisis de subsistencia, epidemias, y que se vivieron grandes deficiencias en la higiene de carácter estructural. Finalmente, resulta un espacio sumamente interesante y complejo porque en él convergen durante todo el periodo bajomedieval tres religiones -la cristiana, la musulmana y la judía- con un peso demográfico variable según la región, y que nos permiten indagar en un rico y complejo mundo de relaciones sociales. Aquí se desarrolló una nueva imagen de la salud y una nueva valoración de la ciencia y de la técnica, y esta situación multirracial y multicultural produjo el encuentro de muy distintas personas dentro de un mismo territorio, hecho que tuvo su reflejo en una enorme complejidad en las relaciones científicas y médicas, llenas de luces y sombras, basadas en el entendimiento y en el conflicto, nunca de forma permanente, ni en uno ni en otro sentido.

Es en este marco espacial y temporal donde desde hace décadas un grupo de historiadores, con Luis García Ballester a la cabeza, hemos realizado un vaciado exhaustivo de fuentes relacionadas con la salud, la enfermedad y los practicantes de la medicina en el sentido más amplio, durante los siglos XIII, XIV y los inicios del XV, en archivos de todo tipo (notariales, municipales, reales, eclesiásticos). Efectivamente, el corpus documental que se ha reunido durante todo este tiempo por distintos investigadores, así como las tesis de licenciatura, tesis doctorales y una gran cantidad de artículos y diversas monografías que se han ido elaborando, permiten un acercamiento sumamente amplio y profundo al tema, a pesar de que todavía son muchos los puntos que quedan por aclarar. He de señalar que habitualmente esta documentación nos ha aportado más información sobre asuntos relacionados con la familia, las inversiones económicas, la participación en los gobiernos municipales, etc., de los sanadores, que no sobre sus actuaciones propiamente médicas. Sin embargo, esta documentación resulta fundamental para entender en toda su magnitud quiénes fueron estos practicantes de la medicina, qué rol jugaron dentro de la sociedad, y si sirvió su oficio para mejorar su condición económica, su poder y su prestigio. 
Durante la segunda mitad del siglo XIV, la institucionalización de un sistema médico muy concreto y con él la medicalización de la sociedad, ocupaba ya un lugar muy relevante dentro la Corona de Aragón. La visión positiva que se tenía desde las instituciones públicas y las instancias privadas es un hecho bien visible. Los dedicados a sanar, en sus variadas vertientes, eran considerados piezas imprescindibles para el buen funcionamiento de la sociedad. Por eso el conocimiento médico y su difusión se debe poner en estrecha relación con las necesidades del cada vez más complejo mundo urbano medieval. Desde las ciudades estos sanadores se dirigirán muchas veces hacia los contornos rurales donde ejercerán su tarea. Así, una red asistencial, no diseñada ni centralizada desde el Estado, se había establecido por todo el territorio de la Corona y, de esta manera, los diferentes tipos de sanadores consiguieron una importancia inusitada en muchos ámbitos sociopolíticos conforme avanzaba el siglo XIII y sobretodo el XIV, ya que la sanidad y la asistencia a los ciudadanos fue cada vez más un objetivo de las autoridades civiles y eclesiásticas (nobleza, monarquía o consejos municipales). Más allá del ámbito propio de la ciudad, la medicina se convertiría en un asunto de gobierno, de la res publica.

Podemos recordar la gran influencia que algunos físicos y cirujanos mantuvieron sobre el régimen de vida y el tratamiento de las enfermedades de los miembros de la familia real, desde el nacimiento a la muerte, aunque también estuvieran rodeados de barberos y boticarios que les aseaban y abastecían de medicamentos. Su intervención en importantes decisiones de los monarcas, y quién sabe si en muchas otras que nunca llegaremos a conocer, es una muestra de la gran confianza en la medicina escolástica y sus practicantes $^{2}$.

En este sentido, la presencia del personal médico en los ejércitos (en tierra o mar) se hace cada vez más clara, y ya desde los inicios del siglo XIV no se puede entender una campaña militar sin el reclutamiento de físicos y boticarios, pero muy especialmente del personal más experimentado en las necesidades de la vida de campaña, los cirujanos, los barberos y también los menescals, como se conocía en territorio catalanoaragonés a los que trataban y curaban equinos. Hay que recordar el clima bélico en el que se vio inmersa toda Europa, sobre todo durante el reinado de Pedro el Ceremonioso (13361387), para entender la relevancia cada vez mayor de este personal médico ${ }^{3}$. La guerra devino, en definitiva, un auténtico laboratorio de aprendizaje para los barberos y los cirujanos. De esta manera, la demanda de estos sanadores fue mayor cuanto más avanzaba el tiempo, también, por supuesto en las galeras $^{4}$. La conducta de la monarquía fue igualmente imitada por la nobleza

\footnotetext{
${ }^{2}$ Sobre la relación entre los médicos y los reyes véase más adelante la nota 43.

${ }^{3} \mathrm{R}$. D'ABADAL, Pere el Cerimoniós $i$ els inicis de la decadència politica de Catalunya, Barcelona, 1986.

${ }^{4}$ L1. CIFUENTES, Medicina i guerra a l'Europa baix-medieval: La sanitat i la participació dels seus professionals en les expedicions militars de la Corona d'Aragó, 1309-1355, tesis doctoral de la Universitat Autònoma de Barcelona, 1993 [ed. en microfichas: Bellaterra, Universita Autónoma de Barcelona 1995]. Publicada parcialmente en M. R. MCVAUGH i Ll. CIFUENTES,
} 
civil y eclesiástica que introdujo el personal sanitario entre los personajes que conformaban su corte particular ${ }^{5}$.

Numerosas circunstancias en los núcleos poblados, de los más pequeños a las grandes urbes, requerían los servicios de los entendidos en medicina. Así por ejemplo, fueron contratados (cirujanos primordialmente) en las instituciones judiciales para peritar la gravedad de las heridas sufridas durante los numerosos enfrentamientos vecinales, o bien para detectar la presencia de enfermedades contagiosas y de enfermos juzgados peligrosos, como los leprosos; intervenían en los mercados de esclavos para tasar su valor en la compraventa, en la atención de los enfermos en los hospitales, en los baños públicos o en las prisiones; la valía de su consejo, a menudo buscado por los gobiernos municipales a la hora de considerar la puesta marcha de ciertos cultivos (arroz) u otros problemas de salubridad urbana (contaminación de aguas, suciedad en las calles, etc.), eran todos síntomas, en definitiva, de un proceso de gradual medicalización de la sociedad, que les convirtió en una pieza clave de la organización política ${ }^{6}$.

Regimen Almarie (Regimen castra sequentium), en L. GARCIA BALLESTER, J. A. PANIAGUA i M. R. MCVAugh (eds.), Arnaldi de Vilanova Opera Medica Omnia, X.2, Barcelona, 1998; también Ll. CIFUENTES Y L. GARCÍA BALLESTER Els professionals sanitaris de la Corona d'Aragó en La medicina en las galeras de la Corona de Araón", 9 (1990), pp. 183-214; Y Ll. CIFUENTES, barbero y sus libros, "Medicina \& Historia", 4 (2000), pp. 1-16.

${ }^{5}$ Un ejemplo claro del mimetismo de este comportamiento nobiliario con respecto a la realeza nos lo proporciona la contabilidad de Alfonso el Viejo, duque de Gandia, marqués de Villena y conde de Dénia. Gracias a la contabilidad de diversos años de esta casa nobiliaria sabemọs que de ella formaban parte los siguientes sanadores: el físico Bernat de Flores, el barbero Antoni Roca y los boticarios Berenguer Cantosa y Bernat de Guda. En principio todos ellos percibían una quitació trimestral, que en el caso del primero únicamente aparece como una aportación salarial, quitacio trimestra, que en el caso de primero unicamente aparece como una aportacion salarial, conocido del boticario Guda. ARV, MR, núm. 9601 (1369); núm. 9592 (1394-95); núm. 9586
con (1398).

${ }^{6} \mathrm{El}$ trabajo más completo sobre el rol social jugado por los médicos y la relevancia de la medicina hasta la Peste Negra en la Corona de Aragón y que en buena medida puede hacerse extensible al resto de la Edad Media y el Renacimiento, es hasta la fecha el de M. R. MCVAUGH, Medicine before the plague. Practitioners and their patients in the Crown of Aragon. 1285-1345, Medicine before the plague. Practitioners and their patients in the Crown of Aragon. 1285-1345, GARCÍA BALLESTER, La medicina a la Valencia medieval. Medicina i societat en un país medieval GAditerrani, València, 1988 . Estudios recientes sobre localidades valencianas en C. FERRAGUD Mediterrani, València, 1988. Estudios recientes sobre localidades valencianas en C. FERRAGUD, Medicina i societat a Alzira durant la Baixa Edat Mitjana, en "Actes de la X Assemblea d'Història de la Ribera. Riuades i innundacions a la Ribera del Xúquer en la perspectiva

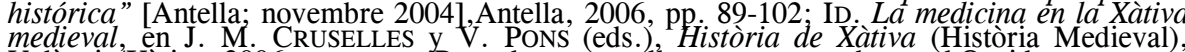
medieval, en J. M. CRUSELLES y . PONS (eds.) Història de Xàtiva (Història Medieval), resulta fundamental L. GARCIA BALLESTER La búsqueda de la salud. Sanadores y enfermos en la España medieval, Barcelona, 2001, pp. 205-212, y, en particular, el capítulo segundo. El caso italiano resulta un referente básico para entender dónde y cuándo nacieron las principales competencias médicas en la ciudad. Véase V. NUTTON, Continuity or rediscovery? The city physician in classical antiquity and medieval Italy, en A.W. RUSSELL (ed.), The town and the state physician in Europe from the Middle Ages to the Enlightment (Wölfenbüttel Forschungen, 17), Wölfenbüttel 1981 pp. 9-46, especialmente pp. 24-34. Sobre aspectos asistenciales concretos los estudios son pp. 9-46, especialmente pp. 24-34. Sobre aspectos asistenciales CIFUENTES, Els banys de Caldes de Montbui, de l'êpoca medieval a la Il lustració, en História CIFUENTES, Els banys de Caldes de Montbui, de l'epoca medieval a la Il lustracio, en Historia
termal de Caldes de Montbui, Caldes de Montbui, 2002, pp. 47-96, especialmente p. 66); termal de Caldes de Montbui, Caldes de Montbui, 2002, pp. 47-96, especialmente p. 66), (hospitales A. RUBIO VELA, Pobreza, enfermedad y asistencia hospitalaria en la Valencia del
siglo XIV, València, 1984; (dessospitació) M. GALLENT, Precedentes medievales de la medicina legal: la dessospitació en el Reino de Valencia "Saitabi", 50 (2000), pp. 11-28; (salubridad) F. ROCA TRAVER, El tono de vida en la Valencia Medieval, "BSCC", LVIII (1982), pp. 2389-308, y continuación en "BSCC", LIX (1983), pp. 1-81 (tiene una tirada aparte). 


\section{LAS OCUPACIONES RELACIONADAS CON LA SALUD}

No resulta sencillo describir y delimitar con precisión el conjunto de oficios y profesiones destinados a realizar todas las actividades médicas citadas anteriormente durante la Baja Edad Media, ya que las nomenclaturas son diversas y los perfiles de actuación poco precisos. Cabe señalar que hubo un programa ideal que marcó una tendencia a la circunscripción de la práctica médica a tres niveles: física, cirugía y boticaria. Se basaba en una vieja concepción escolástica que separaba el trabajo intelectual del manual. Pero la dignificación de este último a partir de los inicios del siglo XIII, permitió incorporar la medicina al campo de la scientia, integrándose en el conjunto de las artes liberales y superando el estrecho esquema del Trivium y el Quadrivium. Fue el galenismo renovado, y plenamente nutrido de aristotelismo durante el siglo XIII, el que permitió diagnosticar enfermedades, conocer sus causas y ofrecer un tratamiento, básicamente porque como paso previo se comprendían los elementos constitutivos del cuerpo. En realidad, esta jerarquía en el mundo de la medicina vino unida al creciente proceso de división del trabajo, junto con la voluntad de los físicos de proteger su lugar privilegiado en el mercado de la práctica médica, y quedó consagrado por el filtro de los exámenes y la expedición de licencias obligatorias por parte de las autoridades ${ }^{7}$. A pesar de todo, esta delimitación de tareas no fue real, ni tampoco se cumplieron las normativas legales a propósito del control de la práctica, y la ambigüedad presidió la actitud de las autoridades, que lo mismo condenaban a los sanadores no examinados, que entregaban licencias sin ningún tipo de reservas, incluso a mujeres que tenían por ley prohibido el ejercicio de la medicina; pero sobre todo judíos y musulmanes practicaron la medicina sin ningún tipo de licencias, porque de hecho fue la competencia del sanador el factor que dictó su aceptación social. ${ }^{8}$

Es bien conocido el proceso de vinculación a la actividad médica de los barberos desde las primeras décadas del siglo XIV, unos años antes de la Peste Negra. Tradicionalmente, los barberos, como su nombre indica, trabajaban únicamente la vertiente higiénica, con lavado, corte y peinado de cabellos o rasurado de barbas. Sin embargo, con el tiempo incorporaron a su oficio el ejercicio de pequeñas operaciones de cirugía (muy frecuente la sutura de heridas) y, sobretodo, la flebotomía o sangría terapéutica, acción muy habitual desde el siglo IX, que comenzarían a poner en práctica para

${ }^{7}$ Reflexiones puestas de relieve en L. GARCÍA BALLESTER, Ciencia y técnica en la Corona de Castilla bajomedieval: problemas y perspectivas, en L. GARCIA BALLESTER (dir.) Historia de la ciencia y de la técnica en la Corona de Castilla. Edad Media, vol. I, Valladolid, 2002, pp. 13-55.

${ }^{8}$ L. García Ballester, M.R. MCVAugh y A. Rubio Vela, Medical licensing and learning in fourteenth-century Valencia, en Transactions of the American Philosophical Society, 79, part
6 (1989). 
completar lo que debían ser unos pobres ingresos ${ }^{9}$. Con el paso del tiempo resultará imposible definir por cuál de las dos ocupaciones ingresaban mayores ganancias, porque muy probablemente sus clientes coincidirían y, aprovechando la misma visita, harían uso de los distintos servicios que se ofrecían en la barbería. En realidad, y tal y como era entendida la medicina en la época medieval, el barbero ejercía una ocupación que contribuía a mantener la salud en cuanto que hacía más higiénicos los cabellos, siempre plagados de piojos, lavándolos y recortándolos, y rasurando también las barbas de los hombres. Junto a esto, la limpieza y la extracción de piezas dentales también estuvo en manos de los barberos-cirujanos, pero fundamentalmente de los llamados queixalers (de queixal=muela) ${ }^{10}$. Así lo ponen de manifiesto determinadas herramientas inventariadas en las casas de estos sanadores.

No fue extraño que los barberos formaran sociedades en las que se contemplaban ambas vertientes, la médica y la higiénica, hecho que confirma su doble ocupación ${ }^{11}$. En definitiva, como se ha dicho ya en numerosas ocasiones, los barberos fueron el auténtico paraguas sanitario de atención al grueso de la población catalanoaragonesa, si bien su predominio parece mayor, y en consecuencia su peso social, político y económico en el Reino de Valencia.

De cómo se materializaba la actividad cotidiana del barbero y la combinación con el resto de los servicios que se ofrecían en su obrador poco se ha escrito. Los ciudadanos podían saber rápidamente cuando se encontraban ante una barbería, ya que estos negocios tenían un elemento distintivo que los identificaba claramente: la cortina. De hecho a la facultad o al derecho de abrir una tienda de estas características se conocía como el derecho de "tener

${ }^{9}$ Véase M. R. McVaugh, Medicine before the plague, cit., p. 40. Junto a las actividades nombradas, el autor cita otras como las de traginer, vendedor de hierro o, incluso, tintorero. Sobre las actividades médicas de los barberos, y en especial sobre la práctica de la flebotomía véase, L. GARCÍA BALLESTER y M. R. MCVAƯGH, Nota sobre el control de la actividad médica y quirúrgica de los barberos (barbers, barbitonsorcs) en los Furs de Valencia de 1329, en Homenatge al doctor Sebastià Garcia Martínez, València, 1988, pp. 73-88, especialmente pp $78 \mathrm{y} 79$. E. A. Hammond ha destacado especialmente la actividad a tiempo parcial de los barberos en el caso inglés, pero sin aportar datos concretos que corroboren esta opinión. Véase E. A. HAMMOND, Incomes of medieval english doctors, "JHM", XV (1960), pp. 154-169, especialmente p. 167.

${ }^{10}$ Sobre los queixalers reales, sus competencias y otros datos sobre el tema véase J. RAHOLA SASTRE, Los "caxales' o 'mestres caxales' del siglo XIV en Barcelona y en la corte rea aragonesa, "Revista Española de Estomatología", 10 (1962), pp. 228-246; Id., Els odontòlegs dels segles XIV $i$ XV a Barcelona, en Actes del T Congrés Internacional d'Història de la Medicina Catalana (Barcelona, 1970), vol. I, Barcelona-Montpeller, 1970, pp. 293-300. Es necesario llamar la atención sobre el fondo de esta literatura contaminada por el deseo de encontrar "precedentes" medievales en la actividad actual. En la Edad Media no se dio un proceso de especialización en los términos en que actualmente entendemos el significado de esta palabra.

${ }^{11}$ Los barberos de Manresa Pere de Comalba y su hijo Tomàs, formaron una sociedad con Ferrer de Comalba, substituido después de su muerte por su hijo homónimo, super officio barberie et arte cirurgie. Las ganancias se repartirían a partes iguales tanto por raure o adobar com per segnar com per offici de cirurgia (AHPM, "Llibre particular de la família Comalba", 1373-1434;9-10-1389). 
cortina" ${ }^{12}$. Este privilegio era concedido por la autoridad municipal a cambio del pago de unos cánones. Pero aparte de este elemento, los barberos utilizaban otros sistemas publicitarios más agresivos, como dejar botellas llenas de sangre en las ventanas de sus obradores fuera de la cortina, lo que llevó a más de una prohibición por parte de los consejos municipales ${ }^{13}$. Un estudio de los inventarios de bienes de los barberos pone de manifiesto que, junto a los instrumentos para la práctica de la cirugía, y en algunos casos de los libros de cirugía y medicina, había todo un elenco de elementos adscritos a la limpieza (sillas especiales, bacines sostenidos en alto por trípodes, toallas) y al afeitado ("raer") de barbas y corte ("aderezar") de cabellos (peines, tijeras, "raors", espejos, etc.), y la indumentaria propia del oficio como el "mandil" de barbero. A todos estos acompañaban siempre utensilios para el afilado del instrumental.

Finalmente, detallaré una situación más obviada en la historiografía, si bien puede intuirse. El obrador de barbería se constituyó en un espacio propio de sociabilidad masculina donde seguramente se desarrolló una vertiente lúdica que debe tenerse muy presente, porque complementa el perfil socioprofesional que se ha considerado tradicional de los barberos-cirujanos hasta bien entrado el siglo XX. Creo que en este sentido, las propuestas hechas para el caso inglés por Margaret Pelling resultan muy sugerentes ${ }^{14}$. Es posible que, sobretodo en las grandes ciudades, el obrador de barbería se convirtiera en un lugar donde se ofrecía, aparte de los servicios habituales, bebida, juego, música y conversación, hecho que dio pie a esta autora a explicar el porqué se insistía tanto en las prohibiciones de no abrir las barberías los domingos. Esta misma prohibición puede encontrarse habitualmente en Barcelona desde principio del siglo XIV. Estos rasgos analizados por Pelling parecen insinuarse en el caso del barbero-cirujano barcelonés Lleonís Mestre. Éste debía pertenecer al sector más acaudalado de entre los barberos, a tenor de lo que indica su inventario de bienes. Sabemos que en su obrador trabajaban él, su esclavo Jordi, así como Joan y Salvador Garriga, con los que

\footnotetext{
${ }^{12}$ Excepcionalmente, el infante Juan, futuro Juan I, concedió a Ramon Vives, barbero de Vilafranca del Penedès, "quod, non obstantibus inibicione quacumque, possitis tenere cortinam et pelves ab opus vestri officii cum sine ipsa non posset comode exercere, quatenus protenditur in latum tabula quam habetis in hospicio vestro, in vico dels Pellicers versus et satis prope hospitium Marchi Laụrador et Petri Dezcortey, et licenciam plenariam impartimur, cum dominus Rex et nos de hiis et similibus veluti in regalia nostra sistentibus ad libitum disponere debeamus". Sin embargo, Vives mantuvo un pleito con un vecino que le acusaba de los perjuicios que le ocasionaba esta cortina y por el hecho de haber ido contra la costumbre de la ciudad cuando el lloctinent del batle general le concedió la cortina por un censo anual de 6 dineros (ACA, C, reg. 1685 , ff. $183 \mathrm{v}-184 ; 5-10-1385$ i reg. 826, ff. 83r-v; 6-6-1382).

${ }^{13}$ Las prohibiciones comienzan a inicios del siglo XIV en Barcelona y continúan encontrándose posteriormente. Véase M.R. MCVAUGH, Medicine before the plague, cit., $\mathrm{p}$. 126 . Prohibiciones Semejantes fueron establecidas en la misma época en la ciudad de Londres. Véase al respecto C.
RAWCLIFFE, Medicine and society in later medieval England, Sutton, 1995, p. 137.

${ }^{14} \mathrm{M}$. PELLING, Occupational diversity: barber-surgeons and the trades of Norwich, 15501640, "BHM", 56 (1982), pp. 484-511, especialmente p. 506. Pelling explica que durante la época moderna en Norwich - una ciudad muy dinámica- los barberos-cirujanos optaron por época moderna en Norwich - una ciudad muy dinámica- los barberos-cirujanos optaron por
utilizar diferentes elementos para atraer clientela hacia sus obradores. No nos es posible justificar utilizar diferentes elementos para atraer clientela hacia sus obradores. No nos es posible justificar este ambiente directamente para la Corona de Aragón. Los inventarios de bienes de barberos y
cirujanos que se conservan son escasos y además pertenecen normalmente a miembros humildes del oficio, hecho que no permite indagar en este aspecto.
} 
compartía los beneficios. En el obrador había seis sillas para la práctica del oficio y también dos bancos, lo que muestra que allí podían atenderse varios clientes a la vez, aunque parece que algunos debieran esperar. Además de las conversaciones que debían sostener los que esperaban el turno, podemos intuir que otros mataban el tiempo con juegos de mesa. Así lo manifiestan los elementos necesarios para la práctica de determinados juegos que aparecían (concretamente el ajedrez y "taules") ${ }^{15}$. La idea es aún más sugerente si tenemos en cuenta que estos obradores solían ubicarse en muchos casos en las plazas de las villas, lugares de contacto y sociabilidad por excelencia. Más complicado resulta averiguar detalles sobre la posible audición musical dentro las barberías. No obstante, tenemos constancia de la afición entre los barberos a practicar el canto y tocar instrumentos.

La existencia de barberías, con diferencias notables en la concurrencia de clientes entre unas y otros, nos conduce a pensar en la importancia de la moda y el prestigio obtenido por un barbero dentro del mundo burgués cada vez más frívolo e interesado por la imagen personal.

Los médicos, en sus dos vertientes, físicos y cirujanos, fueron los más prestigiosos de entre los practicantes de la medicina. Al primero (fisicus/físic) correspondía, como experto teórico en el conocimiento del arte de la medicina, diagnosticar y poner remedio a una enfermedad, mientras que el segundo (cirurgicus/cirurgià) trataba las fracturas, heridas, abscesos y enfermedades de carácter externo. Era muy frecuente, sin embargo, que los dos elaboraran los medicamentos, ya que contaban muchas veces con los conocimientos e instrumental necesario para ello. Incluso llegó a darse la circunstancia, no excepcional, que un notario se convirtiera en médico. Por otro lado, algunos físicos se dedicaron a cultivar la vertiente más intelectual del oficio a través de la escritura y traducción de tratados y la difusión del conocimiento médico mediante la enseñanza en un Estudio General u otros estudios de medicina no generales pero sí reglados. Aunque, tal y como muestran las cantidades que alcanzaban sus salarios como docentes, bien pensado lo más provechoso para ellos era dedicarse a trabajar para miembros notables de la sociedad o bien al servicio del municipio, que podían pagar bastante más ${ }^{16}$. ¿Cómo se justifica pues, esta opción por el estudio y la enseñanza? Para algunos escribir y enseñar se convirtió en la clave a través de la cual lograr una gran reputación y una nutrida y acaudalada clientela, sobretodo, cuando dejaban la docencia. El objetivo, por lo que respecta a la

${ }^{15}$ J.M ${ }^{\mathrm{a}}$ RoCA, Un cirurgià barcelonès de la XVa. centuria, "BRABLB”, 81 (1923), pp. 145161, especialmente pp. 146-147.

${ }^{16} \mathrm{El}$ salario que pagaban los paers de Lleida a los profesores de medicina era bastante inferior al de los docentes en derecho, así como la remuneración que recibían los profesores de los 600 sueldos de Jaca el año 1324 mientras que el 1330 Guillem d'Avinyó cobraba 400 sueldos por por 600 sueldos de Jaca el año 1324 mientras que el 1330 Guillem d'Avinyó cobraba 400 sueldos por leer en arte de cirugía. Véase M. R. MCVAUGH y L. GARCÍA BALLESTER, Medical faculty at los documentos 2 y 4 del apéndice. En la misma época el servicio a algún noble o a algún consejo municipal les hubiera reportado semejantes o superiores beneficios. No tenemos apenas noticias sobre las cantidades que podía reportar la redacción por encargo de un tratado medico. 
tarea intelectual, no estaba puesto en las repercusiones directas de la ganancia, sino en el prestigio y la atracción ulterior de una importante clientela. Ahora bien, no todo es dinero y fama, ni antes ni ahora, y hay que también contar con factores como la propia exigencia intelectual y los gustos del autor. Algunos, incluso fueron muy conocidos por su literatura extramédica ${ }^{17}$.

Otros físicos, en no pocas ocasiones, aceptaron ser contratados por las autoridades municipales como maestros de escuela ${ }^{18}$. Y es que la nueva valoración de la cultura letrada por parte de la sociedad y el escaso número de bachilleres y licenciados en artes en el mercado para cubrir la demanda social, se constituyó en un camino abierto para los médicos y una vía más con la cual lograr ingresos. En numerosas ciudades y villas catalanas y valencianas, pequeñas y grandes, los graduados en artes y medicina consiguieron un protagonismo directo o indirecto en la difusión de las letras, y algunos municipios optaron por ofrecerles contratos para asistir a su población, con la condición de que también se dedicaran a la educación de los jóvenes (Véase el cuadro 1). Pero no siempre fue el deseo de lucro el que movió a estos hombres hacia la docencia. Quizá fue su convencimiento de la importancia que tenía la enseñanza, la valoración de su papel social como difusor de cultura entre una gente que no tenía en su mayoría la capacidad económica ni la necesidad de aprender letras, la que condujo a algunos a ofrecerse para enseñar gramática y lógica a los escolares, sin cobrar salario alguno. Seguramente ya se consideraban satisfechos con el salario que le entregaba el consejo municipal por su contrato anual.

Los boticarios (especier; apotecari) fueron, tal vez, los más dispersos en su actividad. No solamente confeccionaban los medicamentos simples y compuestos, a veces a partir de herborizaciones realizadas por ellos mismos, sino que también actuaban por su cuenta recomendando o suministrando directamente los medicamentos a los enfermos, y tampoco fue infrecuente que ante la ausencia de médicos las autoridades los tomaran para ejercer el papel del físico ${ }^{19}$. Sin embargo, las actividades médicas desplegadas por un boticario

\footnotetext{
${ }^{17}$ Estos serían casos como el de l'Espill, de Jaume Roig, o de algunos poetas hebraicos de profesión médicos. Véase Jaume RoIG, Espill o Llibre de les dones, a cura de Marina Gustà, Barcelona, 1998; E. FELIU y J. RIERA, Poemes hebraics de jueus catalans, Barcelona, 1976.

${ }^{18}$ Así lo ha expresado J. M ${ }^{\mathrm{a}}$. CRUSELLES, Escuela y sociedad en la Valencia bajomedieval, València 1997, pp. 87-88. Pero el fenómeno no es exclusivo en absoluto de la Corona de Aragón. El ilustre cirujano francés Henri de Mondeville utilizó la escuela como fuente de ingresos temporales ante los problemas económicos que atravesaba: oportet me scolas intrare et propter lucrum et victum omni die discurrere hinc et inde, quoniam sub sola Dei gratia parum crassa cum
proprio labore manuum mearum michi et toti familiae necessaria omnia subministro. Citado en proprio labore manuum mearum michi et toti familiae necessaria omnia subministro. Citado en
Ll. CIFUENTES, Medicina i guerra, cit., p. 521 . La direccion de escuelas de gramática por parte de médicos es recogida también en el territorio francés. Véase D. JACQUART, Le milieu medical en France du XIIe au XVe siècle, París, 1981, p. 191.

${ }^{19}$ Sobre la práctica de la boticaría véase C. VELA I AULESA, L'obrador d'un apotecari medieval. Segons el llibre de comptes de Francesc ses Canes (Barcelona, 1378-1381), Barcelona 2003. Era muy frecuente que el mismo físico o cirujano elaborara los medicamentos o que ei boticario actuara como médico. Esto era también evidente en el mundo anglosajón, sobretodo en el caso de los cirujanos, que contaban con todo lo necesario para preparar medicamentos (L.G. Me caso de los cirujanos, que contaban con todo lo necesario para preparar medicamentos (L.G.
MATTHEWS, The royal apothecaries, Londres, 1967, p. 2 ). He podido localizar algunas licencias concedidas a boticarios para ejercer la medicina. Concretamente, Guillem Canet recibía licencia para ejercer el 23 de enero de 1356 (ACA, C, reg. 683, ff. 99v-100). La transcripción de este documento se encuentra publicada en A. LóPEZ DE MENESES, Documentos culturales de Pedro
} 
son muchas veces difíciles de ver y se tiene la impresión de que la vertiente comercial y de intercambio (especias, alimentos, papel, paños, materias primas...) se impone a la sanitaria. De aquí su mención como especiero, de manipulador y vendedor de especias, como también muchos otros productos. A esto hay que sumar una labor artesanal con la producción de cera para la iluminación y para los exvotos, confitería, etc. Su trabajo es tan extenso y variado que resulta extraño que aquellos obradores más dinámicos no cuenten con dos o más aprendices y esclavos.

¿Cómo se integraron las minorías religiosas en este sistema médico? ¿Ejercieron igual que los cristianos estas ocupaciones? ¿Qué papel jugaron las mujeres? En primer lugar aclararé que no se ha descubierto documentación que permita hacerse una idea de los sanadores que practicaban dentro las comunidades mudéjares, ni de ninguna licencia de ejercicio de la medicina en su favor o contrato con municipio. Este hecho está relacionado con la fuga de las elites durante la conquista cristiana del territorio catalanoaragonés y la posterior pérdida del carácter científico de la medicina practicada, que pasó a basarse en el empirismo y la folk-medicina, y se decantó preferentemente por la medicina de los animales (menescalia) ${ }^{20}$.

Respecto a los practicantes judíos, se debe poner de manifiesto la gran capacidad de integración en el modelo asistencial cristiano, hasta el punto que colaboraron en su pervivencia. A pesar de haber quedado excluidos, hay que considerar el buen concepto que los judíos tuvieron del sistema de enseñanza cristiana $^{21}$. No hay un solo lugar en toda la Corona donde exista una comunidad judía, por pequeña que fuera, que no encontremos algún físico o cirujano hebraico ejerciendo entre sus correligionarios, pero también atendiendo a la población cristiana e incluso la sarracena. La fama conseguida por algunos de éstos, y transmitida en forma de grandes beneficios a sus familias, se hace evidente en el caso de los que sirvieron a la corte real y a algunas casas nobiliarias. Debemos distinguir, a pesar de todo, entre los médicos judíos pertenecientes a la minoría racionalista, fuertemente intelectualizados, que fundamentaban su práctica médica en la filosofía natural aristotélica, tal y como lo hacían los médicos cristianos formados en la Universidad, y los que practicaban la medicina casi empíricamente. Tan sólo los primeros pasaban los exámenes de licencia, que estaban basados en el ritos y los contenidos de la medicina universitaria. La realidad era compleja.

el Ceremonioso, "Estudios de Edad Media de la Corona de Aragón (Zaragoza)", 5 (1952), pp. ejercer el arte de física y de cirugía ei 9 de junio de 1369 (ACA C reg 1678 , ff 13r-v). Anton ejercer el arte de física y de cirugía el 9 de junio de 1369 (ACA, C, reg. 1678, ff. 13r-v); Anton Punyet, boticario de Morella, recibía licencia para ejercer la cirugía eĺ 11 de noviembre de 1374 gue tractara a los pobres y a los enfermos del hospital, ante la falta de personal asistencial (L. que tractara a los pobres y a los enfermos del hospital, ante la falta de personal asistencial

${ }^{20} \mathrm{~L}$. GARCÍA BALLESTER, Historia social de la medicina en la España de los siglos XIII al XVI, vol. 1 [=La medicina musulmana y morisca], Madrid, 1976, pp. 29-57.

${ }^{21}$ L. GARCÍA BALLESTER, L. FERRÉ, L. y E. FELIU, Jewish appreciation of fourteenth-century scholastic medicine, "Osiris" 6 (1990), pp. 85-117. 
Cuando la polémica maimoneidiana se agudizó los miembros de la minoría racionalista fueron atacados por el establishment de la aljama.

Algunas investigaciones han ido resituando la gran importancia que tuvieron las mujeres dentro de la práctica médica. Las referencias que se han ido encontrando, aunque dispersas, son clarificadoras, y detalles como la concesión de licencias para ejercer la medicina, cada vez más abundantes en las postrimerías del siglo XIV y los inicios del XV, ponen de manifiesto que, a pesar de la prohibición oficial, la actuación de metgesses era habitual y se les reconocía un alto grado de competencia, también en la corte. Las mujeres con conocimientos y reputación de sanar, incluso famosas por la aplicación de remedios muy concretos - como en la curación de hernias o de enfermedades oculares-, están presentes en la documentación real y notarial, y también en las ilustraciones de los manuscritos, y en estos documentos, como en muchos otros casos, queda claro que la componente empírica era fundamental en su actuación, aunque no se pueda descartar el acceso de algunas a los textos. Hay que poner atención en el hecho de que el escenario que rodea el parto les estaba absolutamente reservado; las matronas (madrines o llevadores), las que toman del suelo al recién nacido, harán aquella delicada y especial tarea de ayudar a parir, hasta que los hombres les irán usurpando progresivamente este lugar a medida que avanza la época moderna ${ }^{22}$. Aunque, hoy por hoy, la documentación no nos proporciona datos suficientes como para acercarnos con garantías al conocimiento de la práctica médica de las mujeres al lado de sus maridos o bien de manera independiente, sobre todo en cirugía y boticaria, se ha puesto de manifiesto que algunas mujeres practicaron la medicina y obtuvieron buenos beneficios y reputación en su tarea. No se debe olvidar que, de entrada, serían las mujeres las primeras en detectar e intervenir en las necesidades de los enfermos de la casa. La transmisión de las experiencias de madres a hijas y la acumulación de sabiduría producto de la cotidianidad, convierten a la mujer en la primera dispensadora de atención médica mientras la enfermedad no se agrave ${ }^{23}$. Una oración y un remedio casero, un buen caldo de gallina o bien una purga o unas píldoras de aquellas que se venden en los mercados o en las boticas, serán el primer paso, con toda seguridad, para solucionar los primeros indicios de enfermedad.

El exceso de los emolumentos cobrados por los físicos y los cirujanos, que forman parte de las críticas populares que han permanecido en el lenguaje de la calle, y la imposibilidad de hacerles frente, o bien la desconfianza, obligarán a buscar vías de atención alternativas. El curanderismo es una de las

\footnotetext{
${ }^{22}$ Debemos las reflexiones más profundas sobre la práctica médica de las mujeres así como su atención a Monica "Green. Véase M. GREEN, Women's medical practice and health care in medieval Europe, "Signs", 14 (1989), pp. 434-473. ID., Documenting medieval women's medical practice, en L. GARCIA BALLESTER, R. FRENCH, J. ARRIZABALAGA, y A. CUNNINGHAM (eds.), Practical medicine from Salerno to the Black Death, Cambridge, 1994, pp. 322-352.

${ }^{23} \mathrm{C}$. FERRAGUD, La asistencia médica doméstica femenina en la ciudad de Valencia durante la Baja Edad Media, "Dynamis" (2007), en prensa. M. CABRE, "Como una madre, como una hija': las mujeres y los cuidados de la salud en la baja edad media, en I. MORANT (dir.), Historia de las mujeres en España y América latina. De la Prehistoria a la Edad Media, Madrid, 2005, pp. 637-658.
} 
vías más frecuentes, tanto en el mundo urbano como en el rural, pero especialmente en el último. Fórmulas entre religiosas y mágicas, juntamente con el empirismo, se combinarán para crear esta figura tan popular. De hecho, esta fue una época en la que, a pesar del triunfo de la medicina universitaria, todo valía con tal de recuperar el bien más preciado del ser humano, que es la salud, como ocurre hoy en día cuando los medios de comunicación de masas han lanzado a la fama un buen número de medicinas alternativas. Y los mismos monarcas lo demostraron continuamente recorriendo a aquellos de quienes habían oído que eran especialmente significados por los remedios para determinadas enfermedades.

El hombre y la mujer medievales viven en un mundo que no se puede entender sin el concurso de la religión. La confianza en la espiritualidad cristiana como un camino hacia la curación es muy significativa. El tapiz que hay en la pared del comedor de un cirujano catalán del Cuatrocientos así nos lo recuerda; Jesucristo, considerado el más grande de entre los médicos, aparece curando un enfermo ${ }^{24}$. De hecho, la eucaristía, y concretamente el cuerpo de Cristo, recibirán unas atribuciones curativas que nos recuerdan que a menudo el pecado es considerado como la última de las causas que explican una enfermedad o una epidemia, entendida como castigo divino ${ }^{25}$. Por ello, en este mundo se debe estudiar todo un conjunto de factores y variables para entender realmente qué hay detrás de la enfermedad y su curación. Incluso el propio monarca era considerado como el canalizador del poder de la divina gracia a través de sus manos. El uso de rogativas sanadoras, encantamientos y conjuros fue una realidad habitual. Si como se pensaba en esta época la enfermedad procedía del pecado, la vida recta era una medicina preventiva ideal y las procesiones y las peregrinaciones podían considerarse como medicinas y antídotos.

\section{EL TRIUNFO DEL GALENISMO Y SUS PRACTICANTES}

Muy pocas fueron las voces contrarias a los médicos y a su práctica, si bien la cáustica burla popular y las advertencias de los moralistas contra los abusos y el afán de lucro y poder de los médicos, han quedado reflejados en la literatura de la época. En cambio, los médicos habían gozado de una antigua imagen ideal de hombre honrado, enamorado de su profesión y de la naturaleza humana y que ofrecía bienestar y salud de forma desinteresada a quien lo solicitara. Esta fue una imagen ética que a lo largo de la Edad Media

${ }^{24}$ Ll. CIFUENTES, La promoció intel-lectual i social dels barbers-cirurgians a la Barcelona medieval. l'obrador, la bibliotecia i els béns de Joan Vicenc (fl. 1431-1464), "ATCA", 19 (2000), pp. 427-479. Sobre la vinculación entre la teología y la medicina J. ZIEGLER, Arnau de Vilanova. Internacional d'Estudis sobre Arnau de Vilanova, vol.'II], pp. 248-307.

${ }^{25}$ P. Laín EnTRALGO, Enfermedad y pecado, Barcelona, 1961. 
se buscó perpetuar ${ }^{26}$. Esto era fundamental en un momento que el médico no cesaba de ganar protagonismo social de manera ininterrumpida. No parece que las miradas recriminatorias con las que habían sido criticados los practicantes de ciertos oficios manuales en algunos lugares de Europa hasta bien entrada la Baja Edad Media, como los relacionados con el contacto con la sangre, tal y como indicaron Jacques Le Goff y Bronislaw Geremek, afectaron a la Corona catalanoaragonesa. El oficio de la barbería era citado como uno de los más indignos en ciertas partes del Occidente europeo, sobretodo por las flebotomías frecuentes que solían practicar. Sin embargo, esta infamia estaba relacionada con la falta de derechos urbanos y corporativos y desaparecería con la consecución y plenitud de éstos. Quizá la celeridad con la que esto se dio en el ámbito catalanoaragonés, y especialmente en Valencia, hizo olvidar rápidamente los tabúes antiguos, y ya desde el siglo XIII el bien común rehabilitaba y legitimaba cualquier profesión. De esta manera, los consejos hipocráticos y del propio Galeno continuarían vigentes en la época bajomedieval y perpetuarían esta imagen tradicional de honestidad, sabiduría y carácter grato del médico con el enfermo.

Hay que considerar, en este sentido, la estrecha conexión entre el campo doctrinal basado en el sistema médico vigente en la época, el galenismo, y la puesta en práctica de sus principios. El concepto de utilitas estuvo ligado a la justificación de la presencia del médico en la sociedad, al demostrar la eficacia de su conocimiento a través de la práctica. El médico se convirtió, según la expresión de Tomás de Aquino - puesta de relieve e interpretada por García Ballester- en el artifex factivus sanitatis (hacedor de salud). Así, gracias a la filosofía natural aristotélica se superaba la mera especulación, y esto permitió encumbrar la medicina al grado de scientia, al justificar la actuación médica en proporcionarle como objetivo fundamental la salud del cuerpo humano ${ }^{27}$.

Con esto se puede comprender perfectamente que después del duro flagelo causado por la peste de mitad del siglo XIV - y también las sucesivas oleadas posteriores-, el prestigio de los médicos, de los practicantes de la medicina en general y de la medicina universitaria en particular, no se hundió bajo la pesada losa de la mortalidad derivada de la plaga, sino más bien al contrario. Los médicos pudieron acreditarse gracias a su implicación, preocupación y coraje ante una atmósfera de terror generalizada. La devoción popular a un determinado practicante se expresó en términos de estima y de honor con rasgos paternalistas y el recurso al médico significó una nueva

\footnotetext{
${ }^{26} \mathrm{~L}$. E. MacKINNEY, Medical ethics and etiquette in the early middle ages: the persistence of hippocratic ideals, "Bulletin of the History of Medicine", XXVI (1952), pp. 1-31. R. FRENCH, The ethics of Gabriele de Zerbi, en A. WEAR, J. GEYER-KARDESCH i R. FRENCH (eds.) Doctors and ethics: the earlier historical setting of professional ethics, Amsterdam/ Atlanta, 1993, pp. 79 97. L. GARCÍA BALLESTER, Medical ethics in transition in the latin medicine of the thirteent $h$ and fourteenth centuries:new perspectives on the physician-patient relationship and the doctors's fee en A. WEAR, J. GEYER-KARDESCH i R. FRENCH (eds.), Doctors and ethics, cit., pp. 38-71.

${ }^{27}$ L. GARCÍA BALLESTER, 'Artifex factivus sanitatis': health and medical care in medieval latin galenism, en D. BATES (ed.) Knowledge and the Scholarly Medical Traditions, Cambridge, 1995,
pp. 127-150.
} 
relación de los hombres con la propia muerte, que se añadía también a la interpretación de como se debían conducir las personas en vida. Tan importante y profunda llegaba a ser la relación del médico con su paciente que posteriormente podía devenir amistad e influjo determinante en las reacciones cotidianas. Esta relación se estrechó debido a que los clientes pedían a los médicos medievales consejos para mantener su salud, petición que era bien acogida, como queda patente en los numerosos tratados escritos en aquellos tiempo - hasta 280, según Darrel Amundsen- dedicados a la prevención y explicación de la enfermedad. Quizá esta defensa desaforada de la implicación del médico sea exagerada, pero no deja de parecer oportuna ${ }^{28}$.

Buena parte de la diferencia entre unos y otros practicantes derivaba de la forma en la que habían conseguido su formación médica. A lo largo de toda la Edad Media, la tarea de proporcionar el conocimiento médico fue ofrecida en función de los distintos contextos sociales y estuvo constituida por una extremadamente variable gama de niveles y formas de organización, sofisticación e intelectualización. En toda la Europa occidental la manera de adquirir esta formación se hizo, en esencia, a través de dos canales: por una parte existía el canal institucional, integrado por los que habían estudiado en una facultad de medicina y estaban en posesión de un grado universitario (bachiller, licenciado, maestro), y por otra estaban quienes se habían formado de acuerdo con un modelo abierto (artesanal) o de libertad de enseñanza ${ }^{29}$. Bien pocos fueron los individuos que pudieron permitirse conseguir un grado a través de las universidades de la Corona de Aragón (Montpellier, Lleida, Barcelona o Valencia) y menos aún de alguna de las prestigiosas instituciones francesas o italianas. La tasa de médicos universitarios para la ciudad de Valencia el año 1363 podemos situarla entre el 1'3-1'5 por diez mil habitantes, tasa que se elevaría al 4-5 a los inicios del siglo $\mathrm{XV}^{30}$. En definitiva, son cifras que se corresponden con países actuales en vías de desarrollo. Estas cifras son válidas también para el resto de la Corona de Aragón en general, pero también para buena parte del continente europeo. La mayor parte de los oficios relacionados con la salud, fundamentalmente aquellos en los que el trabajo manual era la base de su quehacer (barberos, cirujanos, y boticarios) utilizaron este mismo método de transmisión de conocimientos, configurando lo que García Ballester definió como "sistema abierto" de aprendizaje de la medicina, para diferenciarlo de la vía institucional universitaria. Este fue también el método que utilizaron los sanadores pertenecientes a las minorías religiosas musulmana y judía. Hay que indicar que en el caso de los mudéjares

\footnotetext{
${ }^{28} \mathrm{D}$. W. AMUNDSEN, Medical deontology and pestilential disease in the late Middle Ages, "Journal of the History of Medicine", XXXIP (1977), pp; 403-421. Sobre la reputación y la visionn social de los médicos, véase N. SIRAIISI, The physician's task: medical reputations in humanist collective biographies, en A. C. CROMBIE $\mathrm{Y}$ N. SIRAISI (eds.), The rational arts of living collective biographies en A.C. CROMBIE Y N. SIRAISI (eds.), The rational arts of living
$[=$ Smiths College studies in history, vol. L], Northampton/Massachussets, 1987, pp. 105-133.

${ }^{29} \mathrm{~N}$. SIRAISI, Medieval and early Renaissance medicine. An introduction to knowledge and practice, Chicago/Londres, 1990, pp. 48-77.

${ }^{30}$ L. GARCÍA BALLESTER, La medicina, en Col loqui Internacional “Civitas Europa”: L'Europa de les Ciutats i dels camins. Art, Cultura i Societat al segle XV (València 4-9 novembre 1996) [V: Ciència i Tecnologia], inédito.
} 
la documentación conservada ha sido mínima, y esto porque quedaron marginados en buena medida del modelo asistencial dominante a la Corona de Aragón y a muchos otros niveles.

Conviene remarcar que en el mundo urbano existían determinadas ocupaciones que podían convertirse más fácilmente que otras en una vía de promoción social, ya que las posibilidades de enriquecimiento eran mucho mayores. Se trataba de aquellas que eran ajenas al sector productivo y que hay que vincular al sector de los servicios y la distribución. De esta forma, las leyes y la medicina formarían el binomio clave en el sentido del beneficio económico - como demostró hace tiempo Claudio Cipolla-, juntamente con mercaderes, pañeros, boticarios y tenderos ${ }^{31}$. Poco a poco, la formación intelectual en todos estos campos se fue cimentando en el paso por las escuelas municipales y posteriormente pasó por conseguir grados en el derecho y la medicina en los centros universitarios, no sin haber cursado primero el estudio en artes, de carácter propedéutico. Ahora bien, dentro de este mundo hay que hacer la excepción de los notarios y la mayor parte de los practicantes de la medicina. Si bien los barberos y otros prácticos no tuvieron formación universitaria, eso no excluye que hubieran pasado por la escuela de primeras letras en una proporción tan grande o más que los integrantes de otros oficios gremiales, y que usaran tratados útiles para su práctica que pueden encontrarse entre sus bienes. Posteriormente, a través de la contratación con un profesional durante un tiempo determinado, el joven aprendiz podía adquirir los rudimentos propios del oficio y ponerse en disposición de independizarse e instalarse por su cuenta ${ }^{32}$.

¿Podemos afirmar con todo lo dicho que se configuró ya durante la Edad Media la profesión médica, tal y como se entiende hoy? Los estudios dedicados a identificar en qué momento la medicina consiguió esta consideración han sido abundantes desde que en 1966 Vern Bullough pusiera el siglo XVI como el momento en el que se constituía el arte de sanar como una profesión. Resulta obvio que este autor se centró excesivamente en el desarrollo de las universidades para justificar esta realidad, y aún hoy podemos encontrar quien continúa reafirmándose en esta idea ${ }^{33}$. Sin duda, la universidad desarrolló un papel de primer orden en esta consolidación de la medicina. Una de las cuestiones fundamentales es que los conocimientos difundidos por esta institución penetraron la sociedad e impregnaron de su conocimiento y de sus virtudes a las elites gobernantes. Aquellos sanadores

\footnotetext{
${ }^{31}$ C. CIPOLLA, The professions. The long view, "Journal of european economic history", 2 (1973), pp. 37-52.

${ }^{32}$ Sobre las distintas formas de acceso a la profesión médica, véase C. FERRAGUD, Medicina i promoció social a la Baixa Edat Mitjana (Corona d'Aragó, 1350-1410), Madrid, 2005.

${ }^{33} \mathrm{~V}$. L. Bullough, The development of medicine as a profession: the contribution of the medieval university to modern medicine, Basle/New York, 1966 . Thomas Broman, en su estudio sobre la Alemania de finales de los tiempos modernos, ha insistido en el papel desarrollado por las universidades como constitutivas de la identitad profesional (Th. BROMAN, The transformation of German academic medicine, 1750-1820, Cambridge, 1996, pp. 1-12; Introducción). En las notas de esta introducción se puede encontrar una amplia bibliografía sobre el debate entorno a las profesiones en general y a la profesión médica en particular.
} 
que no pasaron nunca por la Universidad, la inmensa mayoría, se beneficiaron de las traducciones a las lenguas romance de las principales obras médicas, y no solamente en la ciudad sino también en al ámbito rural. Podemos afirmar, pues, que los sanadores habían sido influidos en su preparación de manera definitiva por la institución universitaria, aunque el empirismo continuaba siendo fundamental ${ }^{34}$

Las características utilizadas por la sociología funcionalista americana para definir una profesión, y que en una medida u otra han adoptado muchos autores, son: la posesión de un corpus doctrinal propio que proporcione a un grupo social una competencia técnica; la institucionalización de éste (creación de la universidad); la organización profesional para monopolizar la práctica (colegios, gremios); los mecanismos de diferenciación del colectivo (lenguaje técnico, vestido, código ético, etc.); el apoyo en los órganos de poder para afirmar e incrementar el prestigio, el poder y los ingresos, y garantizar el control de los otros profesionales (examinación y expedición de licencias); el autocontrol profesional, con una considerable autonomía en la conducción de los asuntos profesionales, hecho que no reemplaza el sometimiento a los poderes real, municipal y eclesiástico ${ }^{35}$. A menudo, los autores se han decantado por una u otra variable para tildar una ocupación como profesión, pero en buena medida todos estos puntos se dieron durante la Baja Edad Media.

Por nuestra parte, concluiremos que ningún grupo de los que ejercieron la medicina se acopla exactamente a las condiciones necesarias para considerar la aparición de la profesión. Para que eso se cumpliera debería darse la circunstancia de que el grupo con formación universitaria hubiera excluido a todo el resto de los practicantes empíricos y cualquier otro tipo de sanador, hecho que no fue en absoluto posible ni, seguramente, deseado. Además, el éxito de este grupo debería haber llegado inevitablemente después de haber luchado ostensiblemente contra las quejas públicas. Sin embargo, en la Corona de Aragón el aprendizaje y la práctica parece que se institucionalizaron desde las instancias públicas y no por iniciativa de los médicos, aunque seguramente también tuvo mucho que ver su opinión. Los médicos del siglo XIV estaban lejos de concebirse a ellos mismos como una comunidad con intereses y éxitos compartidos. Ellos fueron una parte más de una comunidad más amplia de practicantes en la que no había una clara distinción ocupacional. Aquellos que llegaron a constituirse como médicos lo hicieron a través de diversas rutas, y ni tan solo la aparición de los primeros colegios médicos puede considerarse como un desarrollo de la profesionalización, ya que estos afloran después de que se haya establecido un monopolio en la formación y la práctica médica. Con todo, no debemos olvidar que la medicina era la única

${ }^{34} \mathrm{Ll}$. CIFIENTES, Translatar sciència en romans catalanesch. La difusió de la medicina en català a la baixa edat mitjana i el renaixement, "Llengua \& Literatura” 8 (1997), pp. 7-42. ID., La ciència en català a l'Edat Mitjana i el Renaixement, Barcelona, 2002.

${ }^{35}$ L. GARCÍA BALLESTER, Los orígenes de la profesión médica en Cataluña: el 'collegium'de médicos de Barcelona (1342), en Estudios dedicados a Juan Peset Aleixandre, València, 1982, pp. 129-149, especialmente pp. 129-130. 
disciplina científica los practicantes de la cual habían adquirido un cierto estatus más "profesional" frente a los astrólogos - muchos de ellos médicos por la relación entre ambas disciplinas- matemáticos, alquimistas, etc. ${ }^{36}$

\section{DESNIVELES DE RIQUEZA Y PROMOCIÓN SOCIAL}

Las diferencias internas y la casuística dentro del colectivo que nos ocupa resultan variadísimas, lo que nos obliga a poner mucha cautela a la hora de englobar bajo parámetros comunes aquellos individuos que se dedicaron a la medicina. Entre el rico y prestigioso físico formado en el Estudio General, que suele habitar las grandes y populosas ciudades, o en todo caso los núcleos medios donde ha sido contratado y desde donde se puede desplazar para atender también a otros clientes, como la familia real o algunos miembros de el estamento nobiliario, o bien el rico boticario que cuenta con diversos empleados en su taller (obrador), implicado en numerosos negocios incluso de ámbito internacional, y el barbero que opera en las pequeñas aldeas, se abre un abismo en medio del cual transita un colectivo muy heterogéneo. Los primeros, imbricados en las tramas del poder patricio, forman parte del sector acomodado que domina la vida política local, y los segundos integran a menudo los bandos armados que los secundan. Pero estas diferencias empiezan dentro de una misma comunidad. Así nos lo ofrece el caso de Manresa con unos 690 fuegos en 1370 (3.500 habitantes).

La jerarquía que podemos establecer en Manresa a nivel patrimonial nos marca el patrón que fue habitual en cualquier municipio de la Corona que podamos estudiar. El físico Bernat de Figuerola fue un personaje muy influyente en Manresa. El suyo era el cuarto patrimonio de la villa a inicios del siglo $\mathrm{XV}$, y estaba muy por encima de cualquiera de los practicantes de la medicina, más aún si lo comparamos con el patrimonio menos valorado, el de Joan Bassa. Participó en la vida política ejerciendo cargos y también está relacionado con la monarquía, para la que trabaja eventualmente. Sus bienes son diversos y van desde explotaciones agrarias de importantes dimensiones dispersas en un radio territorial amplio, que alcanza varios kilómetros, y unas rentas elevadas que entran en forma de censos cobrados por las tierras y por censales crediticios. En segundo lugar, aparecen los patrimonios de los boticarios y, finalmente, los de los barberos. Curiosamente, con mucha menor diferencia aparece un cirujano, que por la documentación sabemos que la mayoría de las veces era considerado barbero. En condiciones normales los cirujanos pueden fluctuar entre los niveles alcanzados por la mayoría de los físicos y los boticarios. También llama la atención que los más endeudados

\footnotetext{
${ }^{36}$ Estas reflexiones pertenecen a las conclusiones de Michael R. McVaugh en su libro Medicine before the plague, cit., pp. 241-245, donde el autor se declara abiertamente en contra de la before the plague, cit., pp. 241-245, donde el autor se declara abiertamente en contra de la
consideración de la profesionalización médica en la primera mitad del siglo XIV, a pesar de que pueden apreciarse claros síntomas de los intereses hacia la profesionalización.
} 
suelen ser los más ricos, porque son los que más invierten en negocios de todo tipo y su capital líquido disponible no suele ser elevado.

Hay que tener en cuenta que a la sombra de la vela de una barbería no es posible cosechar las fortunas que proporcionaba la intimidad del estudio de un médico, físico o cirujano, (la habitación destinada a biblioteca personal, cobijo del instrumental y lugar donde se reflexionaba sobre la materia médica), y la visita a domicilio con un contrato ante notario. Situarlos a todos ellos dentro de un mismo grupo social, como ha sido la tónica entre los investigadores, resulta confuso y reduccionista. Para un profesional de la medicina tan posible era alcanzar elevadas cotas de poder, prestigio y riqueza, como caer en la pobreza vergonzante, al menos temporalmente ${ }^{37}$. Sin embargo, observando los datos a nuestra disposición, se puede llegar a la conclusión de que un grupo tan escaso en número dentro de las comunidades, tenía un peso político, económico y social que iba mucho más allá de su peso demográfico. Esto se ha podido constatar en núcleos de población de tamaño mediano, como Manresa y Santa Coloma de Queralt en Catalunya o Morella y Alzira en el País Valenciano, y alguno tan importante como Girona ${ }^{38}$.

Las circunstancias que conducen al éxito profesional y social o bien a la pobreza son complejas. La tradición familiar dentro del oficio es un punto clave a tener en cuenta. Se ha podido observar que la medicina suele generar un utillaje material y cultural muy particular en el seno de las familias, que se transmite de generación en generación y solamente circunstancias inesperadas pueden fragmentar, y que las estrategias familiares juegan un papel clave para mantener el estatus o mejorarlo. Para aquellos linajes que tan sólo condujeron a uno de sus miembros hacia estas ocupaciones, la permanencia dentro del grupo médico fue muy difícil. Las alianzas entre miembros del mismo oficio o de semejante categoría, con individuos afines que practicaban el comercio, la judicatura o incluso pertenecían al estamento nobiliario, fue bien común. La conciencia de que los oficios de curar podían resultar muy provechosos se hace evidente en el gran interés de los padres por conseguir la formación adecuada para sus hijos en el oficio que ellos desarrollaban, sobretodo si era posible que éstos accedieran a los estudios universitarios, lo que sin duda marcaba de forma substancial la posibilidad definitiva de ascenso social ${ }^{39}$.

Luis García Ballester, insistiendo en un punto minusvalorado por la historiografía tradicional, la relación teoría-praxis durante la Edad Media,

\footnotetext{
${ }^{37} \mathrm{C}$. BATLLE, Els Granollachs metges de Barcelona (segle XIV). De la cort del rei a la beneficència parroquial, en M. RIU (dir.), La pobreza y la asistencia a los pobres en la Cataluña medieval, vol 2, Barcelona, 1981-82, pp. 383-414.

${ }^{38}$ Véase como ejemplo el caso de Girona en Ch. GUILLERÉ, Milieu médical géronais au XIVe siècle, en Historie médiévale, vol. I [ = 110 Congrés national des Sociétés savantes, Montpellier, 1985], pp. 263-281.ID., Girona al segle XIV, vol. II, Girona, 1994, vol. II, pp. 361-370.

${ }^{39} \mathrm{He}$ podido reconstruir diversos árboles genealógicos de familias de físicos, cirujanos, barberos y boticarios cristianos, y también de físicos judios, que ponen de manifiesto que durante varias generaciones la profesión médica se mantiene como el centro de gravedad de estas familias, que permite alcanzar un alto grado de prestigio, riqueza y poder en un momento determinado. Véase C. FERRAGUD, Medicina i promoció social, cit., especialmente los cuadros familiares representados y los comentarios del capítulo 1 .
} 
vinculada a la creciente importancia de las artes mecánicas asimilables a las tradicionales artes liberales del quadrivium, remarca la necesidad de encontrar las pautas de explicación del ascenso social de aquellos que utilizaron sus manos para el trabajo y la expansión de la cultura letrada gracias a la Universidad $^{40}$. Esto en el mundo médico se tradujo en el ascenso social de los barberos-cirujanos y de los boticarios, y la progresiva aparición de bibliotecas especializadas, junto a los utensilios propios de su ocupación. Y es que desde que la medicina se institucionalizó, se tendió a establecer una gran barrera entre el practicante especulativo, el físico, y el manual, el cirujano. Durante toda la Edad Media se desencadenó una lucha entre físicos y barberoscirujanos y boticarios, en la que los primeros trataron de someter bajo su control a los practicantes de oficios médicos de carácter manual (mecánicos) sin fundamento teórico, y los segundos trataron de adoptar unos conocimientos teóricos basados también en el galenismo y la filosofía natural aristotélica, que dignificaran cada vez más su posición, objetivo que sin duda consiguieron progresivamente en todo el Occidente europeo ${ }^{41}$.

Ahora bien, el volumen de ingresos estaba relacionado estrechamente con la posibilidad de lograr un patrón, o más frecuentemente varios patrones, poderosos y acaudalados (municipios, nobleza o realeza), lo que dependía a la vez de una formación académica. Obtener algún grado en medicina en el Estudio General era garantía de lograr los puestos de trabajo más apreciados, los mejor remunerados; a quienes aprendían la profesión con el contrato de aprendizaje (afermament), y también, no lo olvidemos, adquirían y estudiaban libros teóricos de su arte, y que por lo tanto no aprendían únicamente con el empirismo, les quedaba el prestigio que podía darles su progresión en el dominio del oficio y la movilidad ocasional hacia los lugares más necesitados de entendidos en medicina. La religión era otro condicionante. Vedado el acceso al Estudio General, a los hebreos y a los musulmanes los quedaba la segunda vía, cosa que recortaba, de entrada, sus posibilidades de progreso social. La fama que obtuvieron los judíos en el buen uso del arte de la medicina y la cirugía, les llevó a conseguir unos beneficios extraordinarios al cobijo de las más altas instancias sociales: la monarquía y la nobleza. A los musulmanes les quedó la práctica de la menescalia (albeitería) donde también obtuvieron un prestigio notable. Citaré, en este sentido, que la familia mudéjar más importante del siglo XIV en la Corona de Aragón fueron los Bellvís, que

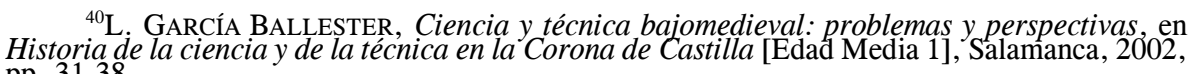
pp. 31-38.

${ }^{41}$ Este fenómeno ha sido muy bien estudiado por Michael R. McVaugh a través de una notable familia de cirujanos de Girona, los Sarriera; tres generaciones de cirujanos (siete personajes en total) trabajaron para la monarquía y el municipio, alcanzando altas tasas de poder y riqueza. Véase M.R. MCVAUGH, Royal surgeons and the value of medical learning: the Crown of Aragon, 1300-1350, en L. GARCíA-BALLESTER, R. FRENCH, J. ARRIZABALAGA y A. CUNNINGHAM (eds.), Practical medicine from Salerno to the Black Death, Cambridge, 1994, pp. 30-59. 
durante tres generaciones fueron albéitares de distintos monarcas, las reinas y sus hijos ${ }^{42}$.

La mayor parte de los practicantes de la medicina, sin embargo, se deben incluir dentro del mundo del artesanado. En las ciudades medievales la célula básica de producción, trabajo y de vida social, todo a la vez, fue el taller familiar. En el seno de esta pequeña explotación se confundían las funciones: el obrador donde se trabajaba constituía una pieza de la casa o habitación, el patrón era el cabeza de familia y el director de la estrategia familiar, algunos hijos aprendían el oficio del padre, como también otros aprendices contratados y la madre echaba una mano en el trabajo, que después le podía servir para conseguir la dirección de la empresa al enviudar. Después, estaban los criados y los esclavos, que ayudaban en las tareas domésticas y en las propias del oficio. En el seno de esta sociedad las relaciones no tenían por qué ser idílicas, pero todo se apoyaba sobre los vínculos del parentesco. Todos vivían bajo el mismo ritmo y formando parte del mismo oficio y cofradía, participando de las mismas fiestas y momentos de alegría y de tristeza.

\section{LOS SANADORES DENTRO DEL PODER POLÍTICO}

Una presencia tan activa dentro de la sociedad tuvo pronto una traducción en la participación en la vida política, en aquellos ámbitos que eran más próximos a los sanadores, generalmente los municipios, cuando fue posible el asentamiento y la estabilidad en un lugar concreto. Algunos llegaron a convertirse en miembros de la nómina de los prohombres, con influencia a nivel comarcal, y aprovecharon su posición para orientar decisiones públicas en beneficio propio. Una muestra, aparentemente no excepcional, de la influencia que pudieron llegar a tener algunos individuos nos lo muestra el caso de Bernat de Figuerola, físico de Manresa. Por su hogar pasaban parientes y amigos solicitando la gracia de su intercesión ante la autoridad real o eclesiástica para garantizarse un futuro, lo que constituye una clara muestra de la influencia como hombres puente entre las elites y los sectores de la población más humildes. Su influencia fue definitiva a la hora de construir un importante canal que derivaría agua del río Llobregat a un sitio tan árido como las inmediaciones de Manresa ${ }^{43}$.

Tres caminos fueron los seguidos por los practicantes de la medicina para integrarse en el mundo de la política: el servicio a la corona y la participación en asuntos internos de los monarcas y otros asuntos de estado;

\footnotetext{
${ }^{42} \mathrm{El}$ estudio más completo sobre esta familia en C. FERRAGUD, La cura d'animals a l'Edat Mitjana. Els menescals i la pràctica de la menescalia a la València baixmedieval, Catarroja, 2007 , en proceso de publicación.

${ }^{43}$ Los casos de Bernat de Figuerola ( $\left.c a .1330-1394\right)$ y su hijo homónimo ( $c a$. 1363-1411) resultan extraordinariamente fascinantes y ricos en matizes. Se trata de dos personajes que, junto con el resto de sus familiares, criados y esclavos, han sobrevivido con gran nitidez gracias a la conservación de los dos protocolos notariales que fueron destinados exclusivamente a la familia y de los que me ocupé en profundidad en diversos apartados en C. FERRAGUD, Medicina promoció social, cit.
} 
los gobiernos municipales; y la adquisición de señorías con vasallos y la transformación en señores feudales.

Efectivamente, la monarquía siempre se sintió muy unida a sus médicos, los cuales regían sus vidas con su atención y consejos para mantener la salud. La profundidad de su relación les hizo acreedores de una confianza plena para tratar incluso sobre los asuntos más delicados de la política de estado. Muchas relaciones entre la corona y los municipios y las aljamas se articularon gracias a la presencia de un físico o un cirujano de prestigio, en uno y otro lugar. Otros sanadores lograron oficialías con prestigio y remuneración, para ellos o para sus familiares. Difícil resulta saber hasta qué punto estos personajes pudieron influir en decisiones trascendentes para la vida de los reinos ${ }^{44}$.

En las postrimerías del siglo XIV se notó un cambio en la procedencia de los integrantes de los cuadros dirigentes de los gobiernos municipales, donde cada vez aparecían más individuos dedicados a las profesiones liberales formados en el Estudio General, sustituyendo en parte a los mercaderes y a los cambistas. En este sentido, los practicantes de la medicina desarrollaron un papel político de primer orden en la organización y el control de los gobiernos municipales, producto de las tareas encomendadas a ellos específicamente y de la entrada directa en el poder a través de los sistemas electivos tradicionales en cada lugar (Cuadro 3).

Se trataba normalmente de los individuos más preeminentes, los mayores contribuyentes del grupo, pero también con un tiempo de permanencia en los lugares más dilatado. Conseguir un cargo público para quien fluctuaba continuamente entre un y otro municipios no era propicio, si bien no se puede descartar. Lo que resulta muy claro es la presencia de practicantes de la medicina cristianos, judíos y musulmanes ejerciendo cargos en los gobiernos locales en cualquier punto de la geografía de la Corona catalanoaragonesa. Ahora bien, los cometidos desarrollados no eran de carácter ejecutivo en las grandes ciudades, reservados estos puestos a un patriciado mucho más selecto, por contra en los núcleos medios se hace notar mucho más la presencia y el poder de médicos y boticarios, pero también a veces de los barberos, a menudo con la presencia de sucesivas generaciones de la misma familia. Con este ejercicio obtuvieron un poder que canalizaron en bien del municipio y el propio; un progreso en la política que en ocasiones les llevó a acceder a la casa real, y por tanto a mejorar su prestigio y consideración social; y una remuneración sustanciosa.

Pero en aquella sociedad el modelo sobre el que todos colocaban el punto de mira era la nobleza. El mimetismo de los comportamientos nobiliarios se hace evidente en muchos aspectos, pero alcanza su culminación con la obtención de una señoría, un castillo con términos propios, con unos

${ }^{44}$ Diversos trabajos permiten captar la relación íntima establecida entre los monarcas catalanoaragoneses y sus médicos: M. R. MCVAUGH, Medicine before the plague, cit. (Jaime II cl Justo); C. FERRAGUD, Medicina i promoció social, cit., (Pedro IV el Ceremonioso); J. M. ROCA, Johan I d'Aragó, Barcelona, 1929 (Joan I); J.M. ROCA, La Medicina Catalana en temps del Rey Martí, Barcelona, 1919. (Martín I el Humano). 
vecinos a los cuales cobrar imposiciones y sobre los cuales ejercer la autoridad judicial. Era un privilegio reservado a unos pocos, los más próximos al rey, los que contaban con formación universitaria y también con mayores riquezas $\mathrm{y}$ dignidad social. Tan solo faltaba coronarlo todo con estas donaciones $\mathrm{y}$, si podía ser, con el ennoblecimiento ${ }^{45}$.

\section{LAS INVERSIONES ECONÓMICAS Y LA OSTENTACIÓN DE LA RIQUEZA}

Con la obtención de unos ingresos más o menos substanciales y con la herencia patrimonial con que ya podían contar, los sanadores se lanzaron a un proceso de inversión en los más diversos y variados campos de la economía. Las posibilidades de hacer negocios fueron durante la Baja Edad Media enormemente amplias. Puede ser que en este punto debiéramos tener en cuenta la mirada atenta y sabia que los diferentes practicantes de la medicina, como buenos observadores de la sociedad que les rodeaba, dirigían a su entorno. Los cambios fundamentales que experimentara el mundo de los negocios, y del mercado en definitiva, no les pasaron desapercibidos, de tal forma que se integraron con las garantías de quien con su mirada escrutadora tiene ventaja sobre una parte de sus competidores, si excluimos, por supuesto, los profesionales del mundo mercantil.

Los más adinerados, ya fuera por compra o por donación, habían logrado explotaciones integradas vinculadas a una masía (Catalunya ${ }^{46}$, una

\footnotetext{
${ }^{45}$ Los físicos reales Joan Amell (propietario de Novalles i Xeresa), Pere Ros d'Ursins (de ascendencia nobiliaria) y Bernat Minguet obtuvieron el ennoblecimiento de manos de Jaime II el primero, y Pedro IV los otros dos. Ramon Querol compró el castillo de Sobreporta (Girona) J. M. MARQUÉS I PLANAGUMÀ, Ensenyament al bisbat de Girona fins a la Il lustració "ATCA", 12 (1993), pp. 273-301. Pero sin duda el caso mejor conocido es el de Guillem Colteller, médico de Pedro el Ceremonioso y su hijo el rey Juan I. El 6 de octubre de 1380 el infante Juan, cantidad y con el depósito añadido de 500 florines más, el mero et mixto imperio et alia iurisdictione domus, forcie loci et parrochie de Spondiliano (Esponellà) (ACA, C, reg. 1766 f. $174 \mathrm{v}$ (6-10-1380; reg. 1727, ff. $91 \mathrm{v}-92$; 7-11-1381). Sobre la venta, además nos hablan otros documentos: Ibid., reg. 1699, ff. 10-14 (8-10-1380); la advertencia de la donación al sotsvegue y el baile de Besalú (Ibid., reg. 1660; 1380, nov. 25) y otra confirmación (Ibid., reg. 1686, ff. $90 v-92 ; 26-7-1381)$. Pueden encontrarse breves noticias sobre el tema en Els Castells Catalans, 9arcelona 1992 . III pp. 207-211 y un breve resumen sobre la donación i los problemas Barcitados posteriormente en J.M. RocA, "Mestre Guillem Colteller", p. XXXIV. En realidad Suscitados posteriormente en J.M. ROCA, "Mestre Guillem Colteller", p. XXXIV. En realidad los intereses del médico en aquel lugar eran anteriores a la venta, pues sabemos que era propietario alodial del mas de Puig de Vallòria, por compra que había hecho al doncel Bernat Sord, y que por esta razón exigía a los habitantes del mas facere recognicionem, iuramento et homagio roboratum, es decir, pretendía su reconocimiento como señor a través del signo más elemental y simbólico del mundo feudal: el homenaje (ACA, C, reg. 1452, ff. 50v-52; 7-12-1378 y reg. 804 ff. 35r-v; 21-1-1379). El rey y su hijo intervinieron obligando a los habitantes del mas a rendirle homenaje y pagar los gastos del juicio También Colteller era propietario de un molino en aquel sitio (Ibid., reg. 1684, ff. 173v-174; 14-1-1379).

${ }^{46}$ En el territori de Barcelona el boticario Ramon de Camp tenia el mas dels Eremites en la parroquia de Santa Maria de Sants, propiedad del monasterio de Santes Creus (AHPB, Joan ciximenis, "(Liber) primum", 22-I-1362/9-IV-1367, f. 165; 27-1-1366) y el físico Arnau Germà Carreres (ACB, Jaume Ferrer, 27-VI-1354/3-VII-1355, f. 47v [28-10-1354]; signatura antigua). En Girona son conocidos los casos de diversas familias de boticarios y médicos propietarios de masos serviles, según Ch. GUILLERÉ, Girona al segle XV, Girona, 1994, vol. II, p. 372. E boticario de Vic Pere de Bertrallans pasó a ser propietario alodial del mas Oller, cuando le fue
} 
alquería (Valencia) ${ }^{47}$, una torre o un castillo, y con eso algunos incluso se habían convertido en señores de vasallos. En la sociedad medieval, a pesar de la importancia cada vez mayor de los centros urbanos y de las actividades que le eran propios (artesanado y comercio), la mayoría de sus componentes continuaban viviendo de los frutos de la tierra - también muchos habitantes de la ciudad - y predominaba una mentalidad en la que consolidar una propiedad agraria era indispensable. De hecho, los ideales imperantes eran los de la nobleza que fundamentaba su riqueza y su prestigio en la posesión de la tierra. De ahí que cada vez más los burgueses (y por supuesto los médicos) pusieron sus miras en obtener unas tierras y una producción suficientemente diversificada que les garantizase el abastecimiento de sus hogares y también unas rentas producto del acaparamiento de censos enfitéuticos.

En sus lugares de trabajo o estudios los médicos no solamente se esforzaban en la lectura y el estudio de los tratados médicos y elaboraban sus registros de atención a clientes, sino que también diseñaban estrategias para canalizar los beneficios de su actividad profesional. Así, pocas inversiones quedaron al margen de éstos, que muy a menudo optaron por la variedad de intereses para asegurar así unas mínimas ganancias, diversificando los riesgos. Crédito, manufactura, comercio, especulación y rentismo son distintas caras del mismo objetivo, rentabilizar las ganancias con inversiones lucrativas y conseguir, al mismo tiempo, una posición relevante dentro la sociedad. Los sanadores, muchos de ellos hombres que sabían de letra y de cuentas, herramientas muy necesarias en sus oficios - lectura de tratados, elaboración de recetas, control de pacientes endeudados, etc. - , se encontraban en una disposición óptima para canalizar estos ingresos. Con sumo cuidado controlaron su participación en el mercado elaborando inventarios y contabilidades privadas con los nombres de sus enfiteutas y el pago de los censos anuales y de los intereses de los morosos a los que habían prestado dinero, o bien anotando los resultados de las grandes y pequeñas empresas mercantiles, sin

vendido por el monarca el 12 de marzo del 1343 por 2.500 sueldos de Barcelona (ACA, C, reg. 990, f. 40v-41v; 12-3-1342). También era propietario de otro mas conocido como de Espolner.", en los términos de Vic, por el cual cobraba unos censos (AHPB, Felip Gombau, "Llibre comú", 20-9-1370/4-III-1371, ff. 27r-v; 29-10-1370). El boticario Joan Ivanyes, alias Gosalbo, y sú esposa Dolca, compraron por 3.700 sueldos quandam alquaream cum orto et terris eldem contiguis sitam in termino Campanar, juntamente con el calderero Jaume Peralada y su esposa contiguis sitam in termino Campanar, juntamente con el calderero Jaume Peralada y su esposa Protocolos, núm. 2605; 8-4-1404).

${ }^{47}$ Jaume d'Avinyó fue un profesional de gran reputación en Valencia, examinador de médicos entre otros cometidos municipales, poseyó al menos desde 1368 la alquería de Vilella, ubicada en el término de Sueca (la Ribera Baixa), y perteneciente al señorío de Montesa. Es precisamente gracias a un pleito mantenido entre el municipio de Sueca y Jaume d'Avinyó, por el pago de la peita, imposición que se negaba a abonar el cirujano por el caráater franco de su posesión peía, imposicion que se negaba a abonar el cirujano por el caracter franco de su posesion -únicamente debía satisfacer una parte de las cosechas-, que sabemos alguna cosa de este alquería se documentan las siguientes tierras pertenecientes a su patrimonio y ubicadas en la huerta valenciana: una tierra plantada de melocotones en la partida de Algirós (ARV, Protocols, núm. 2759; 18-8-1372); una viña en Andarella (Ibid., n. 1008; 1383, gen. 9); dos trozos de tierra vendidos a un agricultor de Burjassot (Ibid., núm. 1009; 9-12-1389); una viña en término de Coscollana (Ibid., núm. 2664; 13-3-1399). 
descuidar el establecimiento de un pequeño "archivo", casi siempre un arcón o cajón de madera, que cobijaba todos los documentos de interés ${ }^{48}$.

Después de observar con detalle la participación en este mundo, llegamos a la conclusión de que las opciones elegidas eran tantas como posibilidades mostraba el mercado, y que esta elección debía estar en función de las estrategias propias de cada familia, y de los individuos concretos, así como de un complejo entramado de circunstancias difíciles de averiguar. Eso afectó especialmente al sector de los boticarios o especieros. Las tareas específicas que estos individuos desarrollaron fueron muy diversas. Sin duda se trata del grupo más dinámico en lo concerniente a la variedad de actividades y de negocios diversos en los que invertían o participaban directamente, dentro del colectivo de los practicantes de la medicina. Pero la implicación en el mundo del comercio no fue exclusiva de boticarios. Los médicos invirtieron también capitales en negocios, ya fuera individualmente o bien formando sociedades de carácter mercantil, muy especialmente relacionadas con la pañería, actividad de gran expansión durante la época. También se dio la explotación de recursos naturales, como la participación en sociedades para la explotación de la madera de los bosques, una actividad muy lucrativa a tenor de la abundante materia prima que se necesitaba. Pero también las riberas del Mediterráneo vieron articularse cada vez más un sustancioso mercado de esclavos, que tenía en los practicantes de la medicina unos clientes habituales, pero también algún especialista en la compraventa. Frecuente fue también la comercialización de productos agropecuarios, ya fuera de los excedentes o de productos directamente cultivados pensando en su salida en el mercado (cereales, productos de huerta, azafrán, etc.), a lo que se añadía la dedicación a la venta de animales -equinos básicamente-, pero también ganado. Añadiré, finalmente, que estas actividades no serán exclusivas de los cristianos y ocuparán también la atención de sarracenos y, sobretodo, judíos ${ }^{49}$.

Todos estos intercambios en los que participaban, tenían un radio de alcance local o comarcal. Hay que recordar que los centros urbanos de orden medio, los predominantes en la Corona de Aragón, se convirtieron en directores y organizadores del territorio, en lugares desde donde se irradiaban los capitales y los bienes manufacturados hacia el campo, mientras que desde éste llegaban los productos tan necesarios para abastecer el creciente mercado urbano. Solo unos cuantos arriesgaron sus bienes en negocios que cada vez se vislumbraban más lucrativos y más seguros con las nuevas técnicas comerciales, a saber aquellos que implicaban la entrada en las redes marítimas internacionales que intercambiaban productos por todo el Mediterráneo occidental.

Finalmente, el aumento de los beneficios económicos se acompañaron del deseo de poner públicamente de manifiesto esta progresión. La mejora de

${ }^{48}$ En el inventario de bienes del cirujano de Manresa Berenguer de Franquedina se pueden encontrar archivadas diversas cartas de contratos y propiedades (AHPM, "Inventariorum IIII", y morosos (AHG, Protocolos [Peralada], n. 1053; 27-8-1344).

${ }^{49}$ Toda esta amplia casuística ha sido estudiada de forma pormenorizada en C. FERRAGUD, Medicina i promoció social, cit. 
las condiciones materiales es obvia en grupos como los barberos y llega a extremos de lujo en los más acaudalados físicos y cirujanos. A la luz de los inventarios, bien podría considerarse que algunos de los miembros del estamento médico podían sentirse aludidos con las críticas de los frailes predicadores de aquel tiempo a propósito de los excesos de la moda. La obsesión de los potentados por diferenciarse de los humildes se hace evidente y la "moda" nacerá para disgusto de predicadores como Francesc Eiximenis, que encontraron abominable aquel camino de dispendio durante los frecuentes cambios que experimentaban las tendencias y que eran imposibles de seguir por los más humildes. Se trataba, en definitiva, del mimetismo de la burguesía dispuesta a hacer suyas las costumbres de la nobleza, y de hecho la imitación de los signos y los símbolos nobiliarios será cada vez mayor ${ }^{50}$.

La casa, a menudo también lugar de trabajo donde se ejerce la medicina, se ubica estratégicamente en el entramado urbano; las plazas, los mercados y las entradas a las ciudades son los lugares escogidos. De esta manera, los ciudadanos saben perfectamente en qué espacio concreto de la ciudad pueden encontrar fácilmente asistencia médica. Esto puede observarse en el caso de la ciudad de Barcelona, de la cual disponemos de los datos de los censos militares conocidos del 1378 y 1389, así como diversos fogajes realizados los años 1363, 1378, 1390 y 1399; completado con las noticias que nos aportan los protocolos notariales (1360 y 1386). Con ellos podemos hacer una aproximación de cuáles eran básicamente los lugares donde residían los practicantes de la medicina y dónde practicaban su tarea. Para realizar los fogatges, indispensables para el cobro de impuestos, la ciudad se dividió en cuatro cuarteles, de una forma artificial y con una finalidad puramente administrativa, a partir de una piedra situada en la plaza del Blat. Una primera ojeada manifiesta que hay una difusión de practicantes de la medicina por todo el perímetro urbano, desde el centro del burgus romano, hasta las periferias y especialmente el Arrabal. Eso demuestra que todos los habitantes de la ciudad podían tener a su alcance una asistencia médica porque existía una distribución geográfica amplia de los sanadores dentro el espacio urbano barcelonés. Se da una concentración importante en el cuartel del Pi donde en realidad en una buena parte, el $86 \%$ de sus habitantes, se dedicaban a la agricultura. Eso se explica porque en la parte norte de la ciudad se encontraba una ancha superficie no urbanizada de terrenos hortícolas que servían para abastecer la ciudad y que habían estado protegidos por la muralla durante este siglo. Por el contrario, en el centro de este cuartel se configuró una área de

\footnotetext{
${ }^{50}$ Para un planteamiento general F. BRAUDEL, Civilización material, economía y capitalismo. Siglos XV-XVIII. 1. Las estructuras de lo cotidiano, Madrid, 1984, pp. 265 y 284-285. Esta Sigcitud de asimilación del molo de vida noble a través de este y p. 265 y 284-285. Esta actitu de asimila cotidiana, como es la comida, ha sido abordado para el caso catalán y valenciano en J. AURELL, Els mercaders catalans al quatre-cents. Mutació de valors i procés d'aristocratització a Barcelona (1370-1470), Lleida, 1996, pp. 74-76 y J.V. GARCÍA MARSILLA, "El buen orden. Imagen pública y refinamiento de las costumbres", en A. FURIÓ (dir.), Historia de Valencia, Valencia, 2000, pp. 174-176,ID. La jerarquía de la mesa. Los sistemas alimentarios en la Valencia bajomedieval, Valencia, 1993.
} 
servicios destinada a cubrir las necesidades del poder civil y religioso - la abundancia de presbíteros, por ejemplo, es muy elevada. Allí residían una amplia nómina de escribanos, juristas y procuradores, y con ellos, también los practicantes de la medicina. En definitiva, la calle de la Portaferrissa hasta la Plaça Nova, por una parte, y la Boqueria, los alrededores de la judería o call, la calle de los Especiers hasta la Plaça del Blat, por otra, eran los dos ejes en torno a los cuales vivían y ejercían mayoritariamente los sanadores. Allí, en el centro de la ciudad, se encontraban las instituciones políticas y eclesiásticas más importantes, y los clientes potenciales más acaudalados, y de paso los lugares más concurridos por estar cerca de las plazas donde los intercambios eran muy frecuentes y el tránsito de viandantes muy importante.

En los núcleos urbanos medievales se desarrolló un activo mercado inmobiliario, donde la especulación jugaba un papel importante. Casas, obradores y sus mesas, huertos, corrales y patios, entraban en el juego de los intercambios intramuros. Los que practicaban la medicina necesitaban de amplios espacios donde residir, realizar su tarea cotidiana y donde almacenar productos agrarios, sobretodo el vino, la leña y otros objetos diversos. Eso les obligaba a participar de este mercado más aún cuando su negocio y sus pertenencias iban en aumento, hecho que se hacía especialmente relevante en el caso de los boticarios.

Algunos de estos hogares se fueron llenando de objetos de todo tipo, cada vez más diversos y más lujosos, mientras otros se debían conformar con el rigor más extremo ${ }^{51}$. Con todo, uno tiene la impresión de que los consejos de los autores preocupados por definir la vertiente ética de la profesión médica no eran escuchados por los integrantes del grupo más elitista, muy atentos a los imperativos de la moda y del consumo urbano, y orgullosos de su reputación, la cual se debía manifestar en la ostentación externa, bien ilustrada por las iluminaciones de los manuscritos. De hecho, tomar el pulso, revisar los frascos de orina de los pacientes, diagnosticar y ordenar un tratamiento, es una tarea muy limpia que se puede realizar ataviado con seda y tafetán, frente a la necesidad del delantal para afeitar y sangrar un paciente. A pesar de la valoración cada vez mayor del trabajo manual y la importancia de la técnica, hay que salvar ciertas distancias. Tal vez por eso el uso frecuente de mozos aprendices o esclavos indica, aparte de querer cubrir una mayor cantidad de clientela, el deseo de aislarse del trabajo más "sucio". Médicos o cirujanos importantes, formados en la universidad, había bien pocos; un núcleo de población medio podía disponer como mucho de uno o dos, generalmente resultas de su solicitud y contratación por el consejo

${ }^{51}$ Las deficiencias de conservạción de inventarios de bienes dificultan un alto grado de profundización en el análisis de los interiores domésticos. Apenas podemos ofrecer datos fiables de media docena de ciudades. Tampoco solemos tener noticia de fos inventarios de los grandes físicos reales. Eso sí, los contrastes son espectaculares entre cirujanos valencianos como Francesc físicos reales. Eso sí, los contrastes son espectaculares entre cirujanos valencianos como Francesc Moliner (1399) y Miró de Corçà (1366), o bien un barbero casi indigente como Joan Noguera. Por otro lado existen barberos con gran progresion y hogares muy equipados como los de Vic contrastada del caso de Manresa. Véase C. FERRAGUD, Medicina i promoció social, cit., capítulo VIII. 
municipal. Algunos arraigaban, otros marchaban buscando mejores salarios en comunidades más pobladas y ricas, pero el tiempo que permanecían no cabe duda que su presencia debía hacerse notar en el municipio.

Por otro lado, las inquietudes intelectuales -lectura y música-, apreciables en los instrumentos musicales que poseían y la amplitud de sus bibliotecas, cada vez mayores y con títulos propios de la teología y la espiritualidad, la ciencia y la literatura en general, y las aficiones lúdicas realizadas en la intimidad del hogar, cada vez se fueron sofisticando más con la llegada del humanismo. Se trata de intereses que gozaban y compartían con el resto del patriciado urbano. De hecho, los practicantes de la medicina medieval manifestaban en sus actitudes el lugar social que les otorgó la sociedad atendiendo a la gran valoración que se hizo de su actividad.

Fecha de recepción del artículo: enero 2006

Fecha de aceptación y versión final: enero 2007 
CUADRO 1

MÉDICOS RELACIONADOS CON LA ENSEÑANZA

\begin{tabular}{|c|c|c|c|c|}
\hline Médico & Escuela regentada & Lugar & Años & Remuneración \\
\hline Domingo Rodrigo & $\begin{array}{l}\text { Enseñanza de la gramática y } \\
\text { práctica de la medicina (anual) }\end{array}$ & $\begin{array}{l}\text { Castelló de la } \\
\text { Plana }\end{array}$ & 1379 & 200 sueldos \\
\hline Domingo Rodrigo & $\begin{array}{l}\text { Enseñanza de la gramática y } \\
\text { práctica de la medicina (anual) }\end{array}$ & $\begin{array}{l}\text { Castelló de la } \\
\text { Plana }\end{array}$ & 1389 & 50 florines \\
\hline $\begin{array}{l}\text { Joan Ferrandis, } \\
\text { bachiller en artes y } \\
\text { en medicina }\end{array}$ & $\begin{array}{l}\text { Enseñanza de la gramática y } \\
\text { práctica de la medicina (anual) }\end{array}$ & $\begin{array}{l}\text { Castelló de la } \\
\text { Plana }\end{array}$ & 1382 & 15 florines \\
\hline $\begin{array}{l}\text { Berenguer } \\
\text { Banyeres, metge e } \\
\text { mestre en arts }\end{array}$ & $\begin{array}{l}\text { Enseñanza de la gramática y la } \\
\text { lógica }\end{array}$ & $\begin{array}{l}\text { Castelló de la } \\
\text { Plana }\end{array}$ & 1404 & $\begin{array}{l}\text { Sin ninguna } \\
\text { remuneración }\end{array}$ \\
\hline $\begin{array}{l}\text { Guillem Miravet, } \\
\text { bachiller en artes y } \\
\text { en medicina }\end{array}$ & $\begin{array}{l}\text { Enseñanza de la gramática y la } \\
\text { lógica }\end{array}$ & Elx & 1401 & \\
\hline $\begin{array}{l}\text { Felip de Sant } \\
\text { Naçari y Bartomeu } \\
\text { de Montsó, medicis }\end{array}$ & $\begin{array}{l}\text { Comisionados para examinar a } \\
\text { los maestros de gramática que } \\
\text { enseñaban en el municipio }\end{array}$ & $\begin{array}{l}\text { Morvedre } \\
\text { (Sagunt) }\end{array}$ & & \\
\hline $\begin{array}{l}\text { Pere de Figuerola, } \\
\text { bachiller en artes y } \\
\text { en medicina }\end{array}$ & Regenta la escuela del Cabildo & València & $1359-1364$ & \\
\hline $\begin{array}{l}\text { Ramon Querol, } \\
\text { maestro en artes y } \\
\text { en medicina }\end{array}$ & $\begin{array}{l}\text { Regía la escuela de gramática } \\
\text { de la colegiata de Sant Feliu }\end{array}$ & Girona & $1361-1369$ & \\
\hline $\begin{array}{l}\text { Ramon Querol, } \\
\text { maestro en artes y } \\
\text { en medicina }\end{array}$ & Funda una escuela & Girona & 1393 & \\
\hline $\begin{array}{l}\text { Joan de } \\
\text { Bonaventura, físico }\end{array}$ & $\begin{array}{l}\text { Enseñanza de la gramática y la } \\
\text { lógica }\end{array}$ & La Bisbal & 1381 & \\
\hline $\begin{array}{l}\text { Arnau }[. . .] \\
\text { cirurgicus et } \\
\text { magister gramatica }\end{array}$ & & Puigcerdà & 1361 & \\
\hline $\begin{array}{l}\text { Pere d’Isòvol, } \\
\text { físico }\end{array}$ & $\begin{array}{l}\text { Usant de son ofici de física e té } \\
\text { escola } \\
\text { (usando de su oficio de física y } \\
\text { tiene escuela) }\end{array}$ & Cervera & 1355 & 500 sueldos \\
\hline $\begin{array}{l}\text { Bartomeu de } \\
\text { Tresbéns }\end{array}$ & $\begin{array}{l}\text { Usant de son ofici de física e té } \\
\text { escola }\end{array}$ & Cervera & 1371 & \\
\hline $\begin{array}{l}\text { Berenguer Sabater, } \\
\text { médico }\end{array}$ & $\begin{array}{l}\text { Usant de son ofici de física e té } \\
\text { escola }\end{array}$ & Cervera & 1372, 1377 & \\
\hline $\begin{array}{l}\text { Bernat Valentí, } \\
\text { físico }\end{array}$ & $\begin{array}{l}\text { Físich e mestre de les escoles } \\
\text { de la dita vila } \\
\text { (físico y maestro de las } \\
\text { escuelas de la villa) }\end{array}$ & Cervera & $\begin{array}{l}1398,1399,1405, \\
1410,1411,1417\end{array}$ & $\begin{array}{l}22 \text { libras } \\
(1399) \\
40 \text { florines } \\
(1405)\end{array}$ \\
\hline $\begin{array}{l}\text { Pere Pau, magister } \\
\text { in medicina }\end{array}$ & $\begin{array}{l}\text { Magister scolarium et } \\
\text { medicinis }\end{array}$ & $\begin{array}{l}\text { Vilafranca } \\
\text { del Penedès }\end{array}$ & 1394 & 800 sueldos \\
\hline
\end{tabular}

Fuentes: L. REVEST CoRzo, La enseñanza en Castellón de 1374 a 1400, Castellón, 1930, pp. 42-44 y los documentos del Apéndice (Domingo Rodrigo y Joan Ferrandis); F. RocA TRAVER, El tono de vida, cit.§ 40 (Berenguer Banyeres); J. Hinojosa Montalvo, Textos para la historia de Alicante. Historia Medieval, Alacant, 1990, p. 456 (Guillem Miravet); A. DURAN i SANPERE y F. GÓMEz GABERnET, Las escuelas de gramática en Cervera, “BRABL”, XVII (1944), pp. 7-17; J. M. MARQUÉs i PLANAGUMÁ, Ensenyament al bisbat de Girona fins a la il·lustració, “ATCA”, 12 (1993), pp. 277-279 (Ramon Querol y Jordi de Bonaventura); J. SANCHIS SIVERA, La enseñanza en Valencia en la época foral, “BAH”, CIX 
(1937), pp. 7-80, especialmente la p. 20 (Felip de Sant Naçari y Bartomeu de Montsó); ACP, Joan Torrelles, "Liber extraneorum", 1361 (1361, gen. 14) (Arnau [...]).

CUADRO 2

PATRIMONIO DEL PERSONAL MÉDICO DE MANRESA

\begin{tabular}{|c|c|c|c|c|c|c|c|c|}
\hline & $\begin{array}{l}\text { Edificio- } \\
\text { patio- } \\
\text { obrador }\end{array}$ & $\begin{array}{l}\text { Edificio } \\
\text { agrario }\end{array}$ & Tierras & $\begin{array}{l}\text { Muebles / } \\
\text { alimentos }\end{array}$ & Dinero & $\begin{array}{l}\text { Rentas } \\
\text { de tierras } \\
\text { y crédito } \\
\text { censalista }\end{array}$ & Deudas $^{1}$ & Total \\
\hline $\begin{array}{l}\text { Pere de Barriac- } \\
\text { Bo }\end{array}$ & $2 / 4.240$ & & $3 / 580$ & $\begin{array}{l}\text { 3.600/78s. } \\
6 \mathrm{~d} .\end{array}$ & 2.900 & & 1.400 & 11.398 \\
\hline Joan Satorre-Bo & $2 / 1.944$ & $\begin{array}{l}66 \\
\text { (pallissa) }\end{array}$ & $6 / 1.030$ & 1.265 & 300 & & 580 & 4.655 \\
\hline $\begin{array}{l}\text { Jaume de } \\
\text { Tresseres-Bo }\end{array}$ & $1 / 2000$ & & $4 / 1.020$ & 894 & 220 & & 125 & 4.134 \\
\hline $\begin{array}{l}\text { Francesc } \\
\text { Satorre-Bo }\end{array}$ & $1 / 3.000$ & & $7 / 5.240$ & $2.760 / 236$ & 5.538 & & 1.326 & 16.774 \\
\hline $\begin{array}{l}\text { Francesc } \\
\text { Despuig-Bo }\end{array}$ & $2 / 5.510$ & 700 (trull) & $11 / 150$ & 5.878s.6d. & & 980 & & 13.218 \\
\hline $\begin{array}{l}\text { Pere de } \\
\text { Santacreu-B }\end{array}$ & $1 / 1.320$ & & $2 / 1.420$ & 1.000 & & 3.000 & 500 & 6.740 \\
\hline $\begin{array}{l}\text { Ferrer de } \\
\text { Comalba-B }\end{array}$ & $3 / 1.800$ & & $10 / 680$ & 653s.4d. & 2.000 & 2.400 & & $\begin{array}{l}7.533 / \\
4 d .\end{array}$ \\
\hline $\begin{array}{l}\text { Tomàs de } \\
\text { Comalba-B }\end{array}$ & $4 / 2.500$ & $\begin{array}{l}260 \\
\text { (palomar) }\end{array}$ & 9/3.337 & 2.828 & & 545 & 1.420 & 9.470 \\
\hline $\begin{array}{l}\text { Bernat de } \\
\text { Figuerola-F }\end{array}$ & $2 / 5.220$ & $\begin{array}{l}1.600 \\
(8 \text { masos })\end{array}$ & $16 / 6.080$ & 4.260 & & 8.805 & 200 & 25.965 \\
\hline Joan Bassa-BC & $1 / 300$ & & $1 / 600$ & 967 & & & $664 *$ & 1.867 \\
\hline
\end{tabular}

${ }^{1}$ Las deudas no se han contabilizado en la suma final.

* Le deben 540 sueldos., por el ajuar.

Bo=boticario; $\mathrm{B}=$ =barbero; $\mathrm{C}=$ cirujano $\mathrm{F}=$ físico.

Fuente: Arxiu Històric de la Ciutat de Manresa, Liber Manifesti, 1408-1411.

\section{CUADRO 3}

\section{CARGOS Y ACTIVITADES POLÍTICAS DESARROLLADAS EN MANRESA POR MÉDICOS}

\begin{tabular}{|l|l|l|l|}
\hline Nombre & Profesión & $\begin{array}{l}\text { Años de } \\
\text { ejercicio }\end{array}$ & Actividad pública desarrollada \\
\hline Bernat de Figuerola & F & 1360 & Procurador de la ciudad \\
\hline & & 1361 & $\begin{array}{l}\text { Mensajero enviado por el Consell de Manresa para } \\
\text { negociar un impuesto en la Corte }\end{array}$ \\
\hline & 1362 & $\begin{array}{l}\text { Prohombre/ procurador por el barrio de Sobrerroca } \\
\text { para cerrar la ciudad con muralla }\end{array}$ \\
\hline & & 1363 & Viaja a las Cortes de Monzón \\
\hline & 1364 & $\begin{array}{l}\text { Miembro de una comisión real para investigar el } \\
\text { comportamiento de oficiales reales }\end{array}$ \\
\hline & & 1364 & Jurat (=miembro del Consell) \\
\hline & 1369 & Jurat \\
\hline
\end{tabular}




\begin{tabular}{|c|c|c|c|}
\hline Nombre & Profesión & $\begin{array}{l}\text { Años de } \\
\text { ejercicio }\end{array}$ & Actividad pública desarrollada \\
\hline & & 1369 & Comisionado para exponer problemas al rey \\
\hline & & 1371 & Jurat \\
\hline & & 1371 & $\begin{array}{l}\text { Comisionado para negociar con el duque la reducción } \\
\text { de la participación en el ejército de Manresa }\end{array}$ \\
\hline & & 1374 & Mensajero enviado por el consell ante el rey \\
\hline & & 1386 & Obrero de la ciudad \\
\hline \multirow[t]{6}{*}{ Bernat de Figuerola jr. } & $\mathrm{F}$ & 1395 & Jurat \\
\hline & & 1396 & Miembro del Consell General (CG) \\
\hline & & 1397 & CG \\
\hline & & 1398 & Misión de paz entre bandos \\
\hline & & 1398 & CG \\
\hline & & 1400 & Obrero de la ciutat \\
\hline \multirow[t]{2}{*}{ Galceran de Gostemps } & $\mathrm{F}$ & 1362 & $\begin{array}{l}\text { Investigación del comportamiento de los oficiales } \\
\text { reales en Manresa }\end{array}$ \\
\hline & & 1383 & Ídem. \\
\hline \multirow[t]{5}{*}{ Antoni d'Alsamora } & $\mathrm{BO}$ & 1360 & $\mathrm{CG}$ \\
\hline & & 1364 & Jurat \\
\hline & & 1369 & Prohombre \\
\hline & & 1372 & Síndic \\
\hline & & 1374 & Prohombre \\
\hline \multirow[t]{8}{*}{ Pere de Barriac } & $\mathrm{BO}$ & 1374 & Prohombre \\
\hline & & 1388 & Prohombre \\
\hline & & 1389 & Clavari \\
\hline & & 1390 & Prohombre \\
\hline & & 1393 & Prohombre \\
\hline & & 1394 & Jurat y conseller \\
\hline & & 1395 & Jurat CG \\
\hline & & 1400 & Prohombre \\
\hline \multirow[t]{2}{*}{ Francesc Despuig } & $\mathrm{BO}$ & 1394 & Jurat \\
\hline & & 1400 & Prohombre \\
\hline \multirow[t]{5}{*}{ Bernat de Salesnoves } & $\mathrm{BO}$ & 1364 & Jurat \\
\hline & & 1365 & Recaudador de impuestos \\
\hline & & 1366 & Idem. \\
\hline & & 1367 & Sotsbatlle \\
\hline & & 1369 & Prohombre \\
\hline \multirow[t]{4}{*}{ Francesc Satorre } & $\mathrm{BO}$ & 1362 & Prohombre \\
\hline & & 1364 & Jurat \\
\hline & & 1393 & Prohombre \\
\hline & & 1400 & Prohombre \\
\hline Jaume de Tresserres & $\mathrm{BO}$ & 1383 & Prohombre \\
\hline Ferrer de Comalba & $\mathrm{B}$ & 1374 & Prohombre \\
\hline \multirow[t]{2}{*}{$\begin{array}{l}\text { Pere Domènec de } \\
\text { Comalba }\end{array}$} & $\mathrm{B}$ & 1364 & Jurat \\
\hline & & $\begin{array}{l}1369,1390, \\
1391\end{array}$ & Prohombre \\
\hline Francesc Clavell & $\mathrm{C}$ & 1360 & Prohombre \\
\hline \multicolumn{4}{|c|}{$\begin{array}{l}\text { Fuente: elaboración propia a partir de los registros del Archivo Histórico Municipal de Manresa. } \\
\text { F=físico; BO=boticario; B=barbero; C=cirujano }\end{array}$} \\
\hline
\end{tabular}




\section{UBICACIÓN DE LOS SANADORES EN LA CIUDAD DE}

\section{BARCELONA}

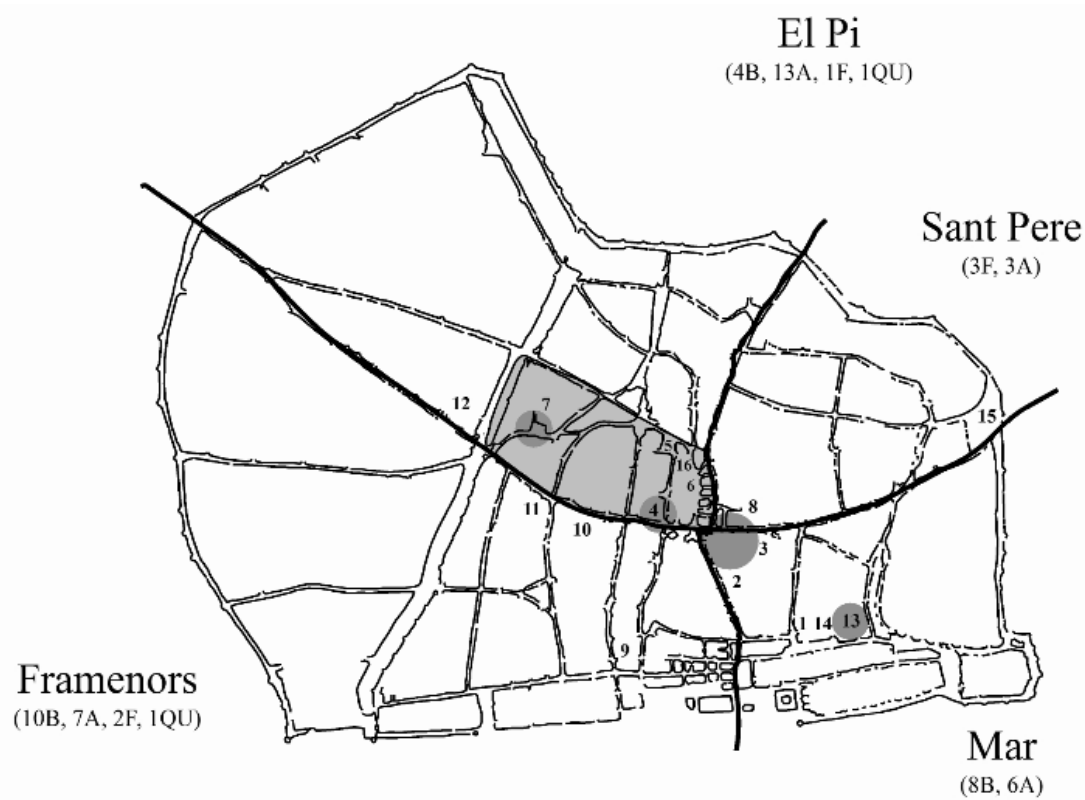

Calles donde se han localizado practicantes de la medicina durante la segunda mitad de siglo XIV.

1. Manzanas entre El Born y L'Esparteria (17A), 2. Calle de L'Argenteria, 3. Calle de la Bòria, 4. Manzana dels Especiers (19A),

5. Plaza Nova (2B), 6. Calle de la Tapineria, 7. Manzanas alrededor de la Iglesia y cementerio del Pi (10A) 8. Plaza de l'Oli (IB),

9. Regomir, 10. Calle del Call, 11. Calle de la Boqueria, 12. Calle de les Cabres, 13. Calle de Sant Joan, 14. Calle de les Olles,

15. Portal Nou (1B, 1C), 16. Plaza del Rei (1FC)

Manzanas donde se concentran el mayor número de sanadores.

Manzanas con mayor concentración de boticarios o especieros.

$\mathrm{A}$-apotecari (boticario), $\mathrm{B}$-barbero, $\mathrm{C}$-cirujano, $\mathrm{F}$-fĩsico, $\mathrm{FC}$-físico-cirujano, $\mathrm{M}$-médico, $\mathrm{Q}$-queixaler (queixal-muela).

El Pi, Sant Pere, Mar y Framenors (Datos según el fogaje de 1389). 